\title{
Reconstrucción paleoambiental de la subcuenca de Xochimilco, centro de México, entre 18000 y 5000 años antes del presente
}

\section{Beatriz Ortega-Guerrero ${ }^{1, *}$, Marco Albán Albarrán-Santos ${ }^{2}$, Margarita Caballero ${ }^{1}$, Ismerai Reyes-Corona ${ }^{3}$, Brayan Gutiérrez-Méndez ${ }^{3}$ y Lizeth Caballero-García ${ }^{2}$}

${ }^{1}$ Instituto de Geofísica, Universidad Nacional Autónoma de México, Circuito de la Investigación Científica, Ciudad Universitaria, Ciudad de México, 04510 México

${ }^{2}$ Facultad de Ciencias, Universidad Nacional Autónoma de México, Circuito de la Investigación Científica, Ciudad Universitaria, Ciudad de México, 04510 México

${ }^{3}$ Instituto Tecnológico de Venustiano Carranza, Av. Tecnológico s/n, Col. El Huasteco,

Lázaro Cárdenas, Puebla, 73049 México.

*bortega@igeofisica.unam.mx

\section{RESUMEN}

Presentamos un registro de las oscilaciones de escala milenaria de un sitio en la cuenca de Xochimilco (parte central de México) entre ca. 18000 y 5000 años cal AP, derivado de indicadores de mineralogía magnética, contenido de elementos mayores y asociación de diatomeas. La edad de la secuencia sedimentaria analizada está definida por el reconocimiento de dos marcadores estratigráficos ampliamente usados en esta región: la Pómez Tutti Frutti del Popocatépetl (ca. 17070 años cal AP) y la Pómez Toluca Superior del Nevado de Toluca (ca. 12320 años cal AP). Adicionalmente, se dispone de una edad $\mathrm{de}^{14} \mathrm{C}$ de un concentrado de ostrácodos. Las variaciones temporales en susceptibilidad magnética $(\chi)$, abundancia de óxidos y oxihidróxidos de Fe (hematita y goethita), minerales magnéticos ultrafinos, titanio, carbón orgánico e inorgánico, así como las relaciones hierro/titanio, calcio/titanio, carbono orgánico/ nitrógeno, silicio/titanio y contenido de diatomeas, indican variaciones en la erosión, origen de los minerales de $\mathrm{Fe}$, salinidad, productividad y origen de la materia orgánica. Estas variaciones responden a oscilaciones climáticas de escalas milenarias. Durante la deglaciación (18000 y 11700 años cal AP), ocurrió una actividad volcánica intensa y este periodo está caracterizado por la dominancia de sedimentación clástica en un lago somero de agua dulce. Los eventos Heinich 1 (frío), Bølling/Allerød (cálido) y Younger Dryas (frío) se documentan con variaciones en la erosión, el contenido de materia orgánica y la precipitación de carbonatos. Durante el Holoceno temprano (117008200 años cal AP), se registraron las condiciones más secas de toda la secuencia. El Holoceno medio (8200-5000 años cal AP) registró un retorno a condiciones húmedas y el establecimiento de un lago de agua dulce, que probablemente favorecieron el desarrollo de comunidades en la ribera del lago.

Palabras clave: oscilaciones climáticas milenarias; cuenca de México; Holoceno; paleoambientes; propiedades magnéticas.

\begin{abstract}
We present a record of millennial-scale paleoenvironmental variations from a site in Xochimilco basin, central Mexico, between 18000 and 5000 years cal BP, using the magnetic mineralogy, geochemical elements content and diatom assemblages. The analyzed sedimentary sequence is chronologically constrained by the recognition of well-known tephra layers widely used as stratigraphical markers in the region: the Tutti Frutti Pumice from Popocatépetl stratovolcano (17070 years cal BP), and the Upper Toluca Pumice (12320 years cal BP) from the Nevado de Toluca, as well as $a^{14} \mathrm{C}$ date from an ostracod rich horizon. The temporal variations recorded in magnetic susceptibility ( $\chi$ ), Fe oxides and oxyhydroxides (hematite and goethite), ultra-fine magnetic minerals, titanium, organic and inorganic carbon, and the iron/titanium, calcium/titanium, organic carbon/nitrogen, silicon/titanium ratios and diatom content indicate fluctuations in runoff, origin of magnetic minerals, salinity, productivity and sources of organic matter. These variations respond to millennialscale climatic oscillations. The deglacial period (18000-11700 years cal $B P)$ was characterized by intense volcanic activity, and the dominance
\end{abstract}


of clastic sedimentation in a fresh water shallow lake. The Heinrich 1 (cold), Bølling/Allerød (warm) and Younger Dryas (cold) events, were recorded in the runoff, organic matter content and carbonate precipitation proxies. The driest conditions in all of the sequence were recorded during early Holocene (11700-8200 years cal BP). The return to more humid conditions and the establishing of a fresh water lake during the late mid Holocene (8200-5000 years cal BP), could promote the settling of communities on the lake shore.

Key words: Millennial climatic oscillations; basin of México; central México; Holocene; paleoenvironments; magnetic properties.

\section{INTRODUCCIÓN}

Las secuencias sedimentarias lacustres constituyen importantes archivos para reconstruir las condiciones paleoclimáticas y paleoambientales de una región. En la cuenca de Chalco, en la parte sudoriental de la cuenca de México, el estudio de estas secuencias ha permitido tener evidencias sobre la evolución limnológica (Bradbury, 1989; Caballero y Ortega-Guerrero, 1998), historia de la vegetación (Lozano-García et al., 1993; Correa-Metrio et al., 2013), régimen de incendios y sequías (Torres-Rodríguez et al., 2015), variaciones paleoclimáticas (LozanoGarcía et al., 2015) y el registro de la actividad volcánica explosiva en los alrededores de la cuenca de México durante el Pleistoceno tardío y Holoceno (Ortega-Guerrero y Newton, 1998; Ortega-Guerrero et al., 2015). El estudio de los sedimentos lacustres de Xochimilco, en donde los estudios paleoambientales son prácticamente inexistentes, permitirá evaluar las hipótesis formuladas sobre los paleoambientes en el centro de México y sus causas, postuladas a partir de los trabajos en el registro de Chalco, principalmente. La existencia de extensos cuerpos lacustres en la cuenca de México (CM) promovió el asentamiento de numerosos grupos sociales desde hace más de 7000 años (Acosta-Ochoa, 2007), y aunque el antiguo lago ha desaparecido casi por completo, en su lecho se concentran alrededor de 22 millones de habitantes (INEGI, 2011). El conocimiento más detallado de las oscilaciones ambientales que afectaron este lago y su entorno durante los últimos milenios son de particular relevancia, considerando la importancia que históricamente ha tenido en esta región la interacción de las poblaciones humanas con el ambiente acuático: este ambiente lacustre constituye el núcleo de la agricultura chinampera del sur de la cuenca de México, por lo que fue declarado Patrimonio de la Humanidad en 1987 por la UNESCO (http://whc.unesco.org/en/decisions/3738). La chinampa es un sistema de agricultura que consiste en la edificación de islotes en el ambiente lacustre por medio del amontonamiento de sedimento del lago sobre esteras y cañas reforzadas con árboles ahuejotes (Salix bonplandiana), o creadas en medio terrestre a través de la canalización del terreno (Palerm y Wolf, 1972).

Para un mejor estudio de climas y ambientes del pasado es necesario un enfoque multidisciplinario en el que se integren diversas líneas de evidencias sobre las variaciones en el lago y su entorno. Por ejemplo, el magnetismo ambiental estudia la relación entre la mineralogía magnética existente en sedimentos y los procesos ambientales. Sin embargo, dado que la mineralogía magnética en un depósito depende de una amplia variedad de procesos ambientales, los parámetros magnéticos no son un registro directo del clima. Para conocer la relación mineralogía magnética-clima, el magnetismo ambiental integra las propiedades magnéticas de sedimentos con indicadores no magnéticos, como los indicadores bióticos (fósiles) o geoquímicos. Dentro de los indicadores bióticos, el análisis de diatomeas, algas con paredes celulares silíceas que se preservan en los sedimentos, permite reconstruir con fidelidad las condiciones fisicoquímicas del lago, que a su vez son un reflejo de las condiciones climáticas regionales. Los indicadores geoquímicos, por su parte, permiten documentar dinámicas de aporte de sedimentos terrígenos al lago o de precipitación de minerales autigénicos, que están directamente relacionados con cambios en los niveles de precipitación y evaporación. Integrando los tres grupos de indicadores paleoambientales es posible establecer los modelos que conectan cada una de las variables con cambios climáticos y ambientales.

En este trabajo presentamos el registro paleoambiental, con base en el análisis de las variables antes mencionadas, de un sitio de la subcuenca de Xochimilco, que abarca de ca. 18000 a 5000 años calibrados antes del presente (cal AP), y lo comparamos con los registros del centro de México.

\section{LOCALIZACIÓN Y CARACTERÍSTICAS GEOLÓGICAS}

La cuenca de Xochimilco ( $\left.19^{\circ} 13^{\prime} \mathrm{N}, 99^{\circ} 08^{\prime} \mathrm{O}\right)$ ocupa la porción sudoccidental de la cuenca de México (Figura 1). Tiene un área de 480 $\mathrm{km}^{2}$, de los cuales la planicie lacustre ocupa $c a .130 \mathrm{~km}^{2}$ y una altitud de 2240 m s.n.m.; está limitada al norte por el cerro de la Estrella y la sierra Santa Catarina, al este por la divisoria que corre entre la sierra Santa Catarina y el volcán Teuhtli, al sur por los conos y otras estructuras volcánicas de la sierra del Chichinautzin (entre ellos además del Teuhtli, Ocuscayo, Cuauhtzin, Chichinautzin y el complejo Guespalapa); y al sur-suroeste por el volcán Ajusco. Al menos 20 estructuras volcánicas se reconocen dentro de esta cuenca. La cuenca de Xochimilco albergó un cuerpo lacustre que en épocas de niveles altos se conectó al norte con el lago de Texcoco y al este con el lago de Chalco. Actualmente los remanentes del lago se limitan a la zona de las chinampas que ocupan un área de $c a .16 \mathrm{~km}^{2}$, y se localizan al noreste de la cuenca.

El volcanismo más antiguo en Xochimilco corresponde al de la sierra de Las Cruces (volcanes San Miguel y Ajusco), compuestos por flujos de lava dacíticos y andesíticos (Romero-Terán, 2001; GarcíaPalomo et al., 2008), cuya edad varía de 2.3 a $0.4 \mathrm{Ma}$ (Mora-Alvarez et al., 1991; Osete et al., 2000; Romero-Terán, 2001; Arce et al., 2008). La sierra Santa Catarina (SSC) está constituida por seis conos de escoria, dos domos andesíticos, un derrame fisural y un cono de tobas de doble cráter, alineados de manera preferencial E-O. La composición geoquímica varía de andesítica, traquiandesítica, basalto traquiandesítico a andesita basáltica (Ortiz-Enríquez, 2017). Las edades obtenidas por ${ }^{40} \mathrm{Ar} /{ }^{39} \mathrm{Ar}$ de la SSC varían de 23 a $132 \mathrm{ka}$ (Jaimes-Viera et al., 2018). El cerro de la Estrella es un cono de escoria ubicado $7 \mathrm{~km}$ en dirección noroeste de la Sierra de Santa Catarina, y es más antiguo que ésta. El campo volcánico de la sierra Chichinautzin (CVSC) se extiende desde el Nevado de Toluca hasta la Sierra Nevada (Bloomfield, 1975; Martin del Pozzo, 1982). Sus productos comprenden escudos, domos, conos de escoria, flujos de lava fisurales de composición basáltica, traquibasáltica, andesítica y dacítica, que emanaron desde 1.2 Ma hasta $1.6 \mathrm{ka}$ cal AP (Siebe, 2000; Siebe et al., 2004, 2005; Arana-Salinas et al., 2010; Arce et al., 2013; Guilbaud et al., 2015).

\section{METODOLOGÍA}

Se colectó un núcleo de $2.47 \mathrm{~m}$ de longitud en el vivero de Nezahualcóyotl ( $19^{\circ} 17^{\prime} 47.98^{\prime \prime} \mathrm{N}, 99^{\circ} 04^{\prime} 55.62^{\prime \prime}$ O), utilizando un nucleador de pistón tipo Livingstone y tubos de acero de $8 \mathrm{~cm}$ de diámetro. En las muestras recolectadas se realizaron análisis de constituyentes sedimentarios, medición de las propiedades magnéticas y concentración de elementos mayores. El análisis de constituyentes sedimentarios se llevó a cabo mediante la observación al microscopio estereoscópico, y a través de la identificación de los componentes en 63 frotis en un microscopio 
a)
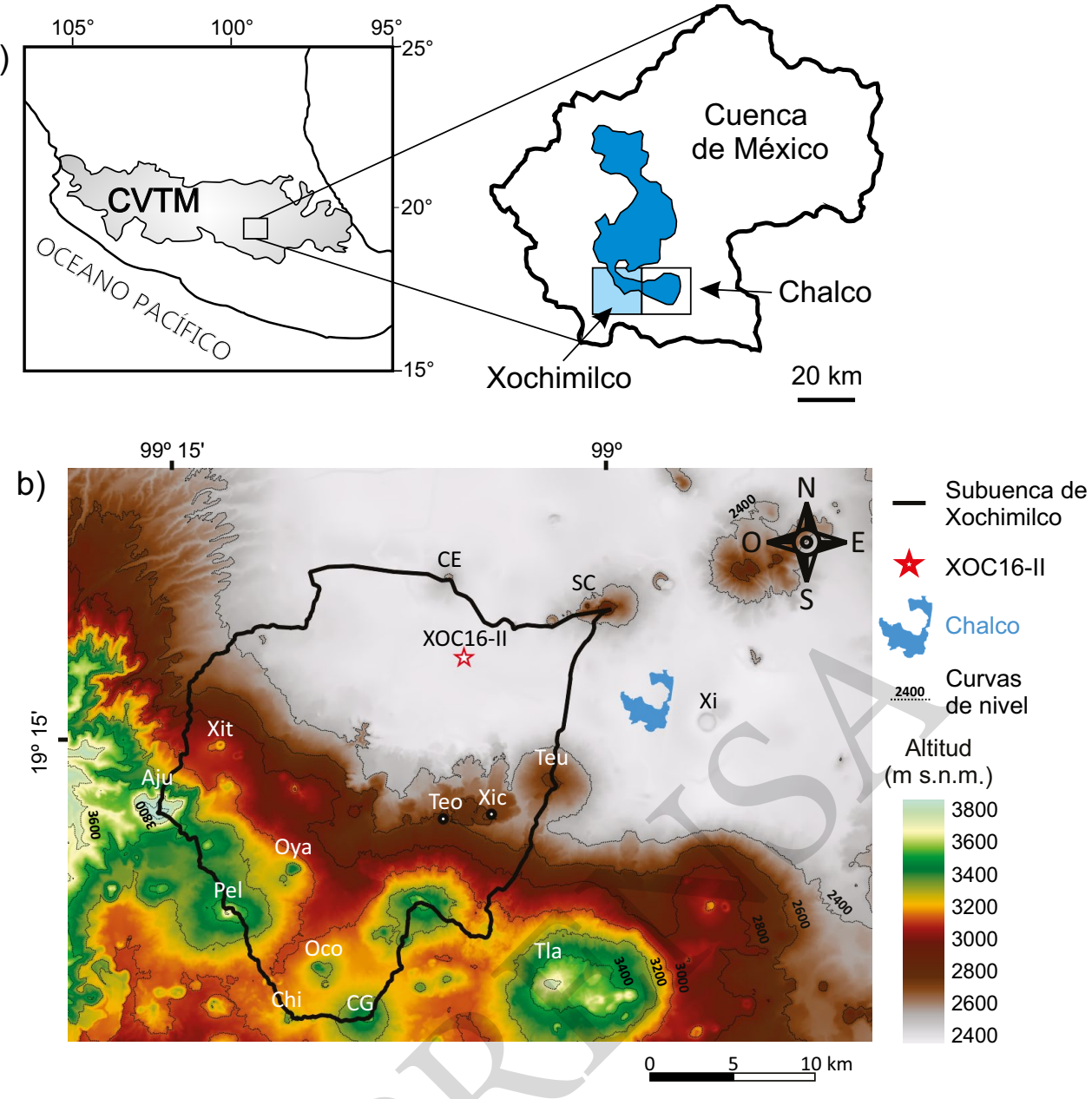

Figura 1. a) Mapa de localización de las cuencas de Xochimilco y Chalco, dentro del Cinturón Volcánico Transmexicano (CVTM). b) Límite de la cuenca de Xochimilco, en la que se muestra la ubicación de algunos de los aparatos volcánicos más importantes: Ajusco (Aju), Cerro de la Estrella (CE), Complejo Guespalapa (CG), Chichinautzin (Chi), sierra Santa Catarina (SC), Teoca (Teo), Teuhtli (Teu), Tláloc (Tla), Ocopiaxco (Oco), Oyameyo (Oya), Pelado (Pel); Xico (Xi); flujos de lava Xicomulco (Xic); Xitle (Xit), así como el sitio del sondeo XOC16-II dentro de los viveros de Nezahualcóyotl y la actual extensión del lago de Chalco.

petrográfico (Myrbo, 2007). La descripción de componentes sedimentarios se basó en el esquema propuesto por Schnurrenberger et al. (2003). Para el análisis de propiedades magnéticas, parámetros geoquímicos y contenido de diatomeas se colectaron muestras cada $10 \mathrm{~cm}$, y a un espaciamiento menor (hasta $2 \mathrm{~cm}$ ) en cambios litológicos apreciables a simple vista. En total, fueron colectadas 47 muestras en cubos de acrílico de $8 \mathrm{~cm}^{3}$ para propiedades magnéticas y en bolsas de plástico para el resto de los análisis.

En la Tabla S1 del Material Suplementario se indican las propiedades magnéticas medidas, la instrumentación utilizada y la interpretación de los parámetros. La susceptibilidad magnética se midió en un sensor Bartington MS2B. La susceptibilidad dependiente de la frecuencia $\left(\chi_{\mathrm{fd} \%}\right)$ se evaluó con la medición de la susceptibilidad magnética en dos frecuencias (976 y $15616 \mathrm{~Hz}$ y campo de $200 \mathrm{~A} / \mathrm{m}$ ) en un susceptibilímetro Kappabridge MFK1-FA de AGICO. Todas las remanencias (MRA y MRI) se midieron en un magnetómetro de giro AGICO JR-6. Se realizaron mediciones de susceptibilidad magnética en función de la temperatura $(\kappa-\mathrm{T})$ en muestras selectas para determinar la mineralogía magnética de acuerdo con las temperaturas de Curie. Estas temperaturas se calcularon mediante el método diferencial de Tauxe (1998). En los ciclos de histéresis se aplicó un campo máximo de 1 T e incrementos de $5 \mathrm{mT}$. A partir de ellos se obtuvo la magnetización de saturación $(\mathrm{Ms})$, magnetización remanente $(\mathrm{Mr})$ y la coercitividad (Hc). La coercitividad remanente (Hcr) se obtuvo por medio de la desmagnetización con campos directos en incrementos de 2 y $5 \mathrm{mT}$ aplicados en dirección opuesta después de la aplicación de un campo de 1 T. En seis muestras se aplicó el método MAX UnMix (Maxbauer et al., 2016), de análisis de distribución de coercitividades para la separación de los componentes magnéticos. Los datos utilizados se obtuvieron por adquisición de MRI en campos directos espaciados uniformemente en escala logarítmica decimal de 10 a $1000 \mathrm{mT}$ (Material Suplementario Tabla S2). De los diferentes modelos elaborados para cada muestra se eligió el de menor número de componentes magnéticos que se ajustase robustamente a la curva suavizada de distribución de coercitividades y que pudiese explicar razonablemente los resultados de las propiedades magnéticas observadas en los procedimientos de laboratorio. Por consistencia con el sistema de unidades utilizado en este trabajo, la coercitividad promedio comúnmente referida en los programas de separación de componentes magnéticos como Bh, se nombra aquí como $\left(\mu_{0}\right)$ Hc. Se reporta la contribución extrapolada (EC) para mejorar la comparación de los resultados con otros trabajos que utilizan distintos métodos de separación (Maxbauer et al., 2016).

La concentración de elementos mayores fue medida en un analizador de fluorescencia de rayos X Thermo Fisher Scientific 
Niton XL3t GOLDD 900. El contenido de carbono y nitrógeno total se determinó en un analizador elemental Thermo Fisher Scientific NC-Soils Analyzer FLASH 2000 Series. Se eligieron algunos elementos y cocientes como indicadores ambientales. El Ti y el Fe se asocian a aporte detrítico (Corella et al., 2012); la tasa Fe/Ti indica la movilización y reprecipitación de Fe (Funk et al., 2004); el Ca puede ser de origen detrítico o autigénico, por lo que la relación $\mathrm{Ca} / \mathrm{Ti}$ se utiliza para discriminar el Ca autigénico y el aumento en la concentración de iones por evaporación (Jouve et al., 2013); la proporción Si/Ti es un indicador de la abundancia de sílice biogénico (Brown et al., 2007). Se midió dos veces el contenido de carbono para determinar el carbono total (CT), y el carbono orgánico total (COT) posterior a un lavado con $\mathrm{HCl}$ para eliminar los carbonatos. El carbono inorgánico total (CIT) se calculó como la diferencia de CT-COT. Los resultados se expresan en porcentaje de carbono de peso seco de la muestra (\%). La relación Corg/ $\mathrm{N}$ se calculó a partir del COT y $\mathrm{N}$ total y se multiplicó por el cociente de los pesos atómicos del $\mathrm{N}$ y $\mathrm{C}$ para presentar los resultados normalizados.

De los mismos niveles seleccionados para análisis químicos, se prepararon 28 muestras para el análisis de diatomeas. Con este fin, se utilizaron $0.5 \mathrm{~g}$ de sedimento seco que fueron limpiados utilizando $\mathrm{HCl}(10 \%), \mathrm{H}_{2} \mathrm{O}_{2} \mathrm{y} \mathrm{H}_{2} \mathrm{SO}_{4}$. La preparación de laminillas permanentes se hizo con $200 \mu$ de material limpio, utilizando Naphrax como medio de montaje. El conteo de diatomeas se realizó en un microscopio Olympus BX50 (1000x) con contraste de fases interdiferencial, en el que se contaron un mínimo de 200 valvas. Para la identificación de diatomeas se utilizó el apoyo de literatura especializada (Krammer y Lange-Bertalot, 1986, 1988, 1991a, 1991b; Patrick y Reimer, 1966). El conteo de diatomeas se transformó en porcentajes y también se estimó la concentración total por muestra, la que se expresa como valvas/g de sedimento seco (v/gss). Los datos se graficaron con el programa TILIA (Grimm, 2004) con el cual también se realizó un análisis de grupos estratigráficamente delimitado (CONISS) para identificar los cambios más importantes en las agrupaciones de diatomeas.

\section{RESULTADOS}

\section{Estratigrafía}

La litología observada en el núcleo XOC16-II se sintetiza en la Figura 2. De acuerdo con los criterios composicionales sugeridos por Schnurrenberger et al. (2003), los sedimentos fueron agrupados en las categorías: clásticos, volcaniclásticos y biogénicos. La mayor parte de los sedimentos clásticos está formada por limo de color pardo y gris con cantidades variables de arcilla y arena. Esta fracción está compuesta esencialmente de silicatos tales como plagioclasa, anfíbol, piroxeno, olivino y minerales arcillosos. Contienen cantidades variables de restos orgánicos: materia orgánica amorfa, diatomeas, espículas de esponja, fitolitos, carbón, restos de plantas, ostrácodos y algas carofíceas. Localmente, presenta cristales de calcita y vivianita autigénica. Los sedimentos volcaniclásticos están compuestos por cinco depósitos de tefra. Entre 2.34 y $2.17 \mathrm{~m}$ de profundidad se encontró un depósito color gris pardo y gris obscuro de lapilli y ceniza constituido por fragmentos de pómez y de granodiorita pobremente clasificados, así como por cristales de piroxeno, anfíboles y plagioclasa. El único depósito de ceniza descrito en la cuenca de México con granodiorita como componente es la Pómez Tutti Frutti (PTF) del volcán Popocatépetl, cuya edad es de ca. 17070 años cal AP (Siebe et al., 1997,

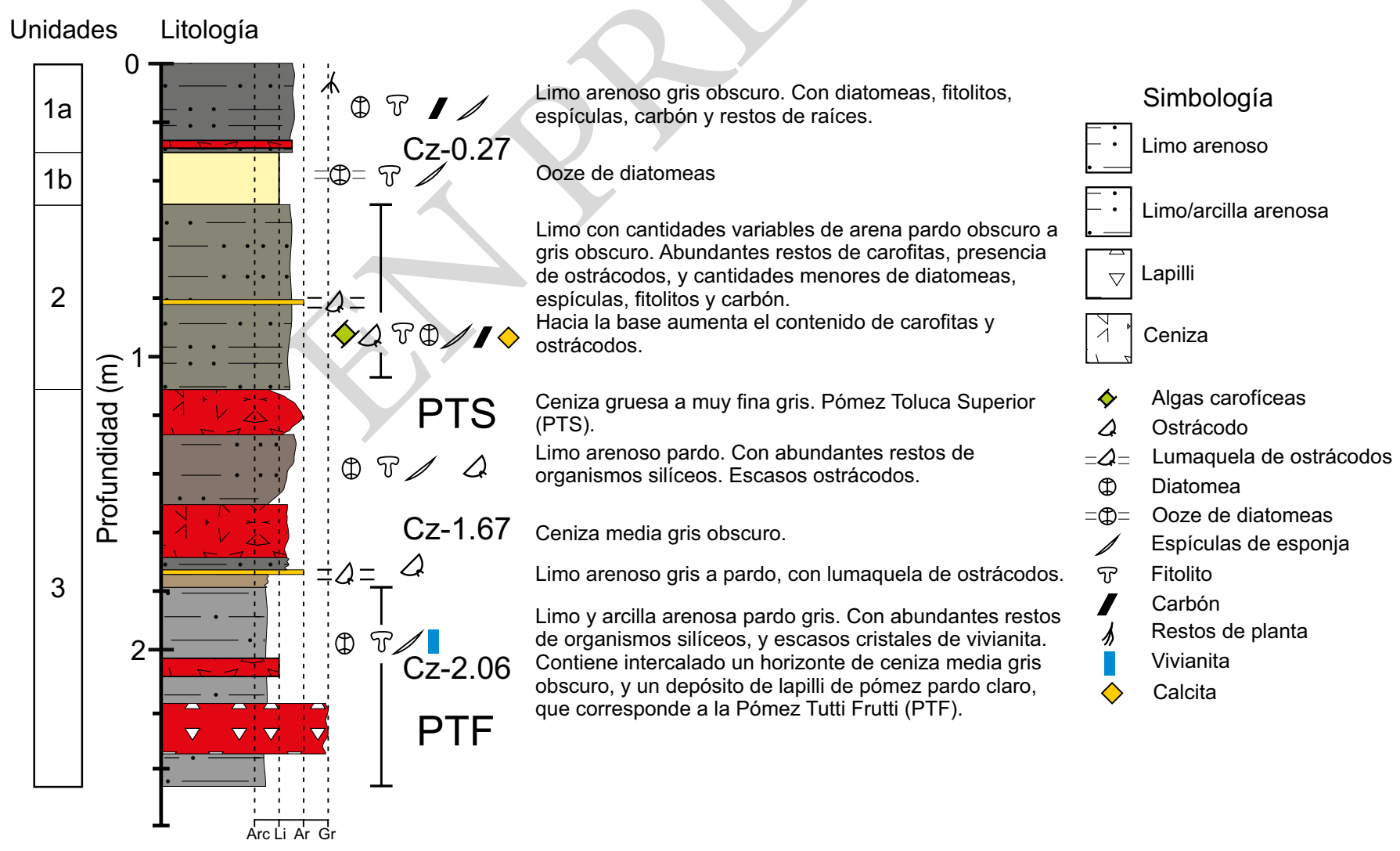

Figura 2. Columna estratigráfica del sondeo XOC16-II. A la izquierda se indican las unidades litoestratigráficas (1-3). PTS: Pómez Toluca Superior; PTF: Pómez Tutti Frutti; Cz-0.27, Cz-1.67 y Cz-2.06: cenizas de origen desconocido. 
Tabla 1. Edades utilizadas en la elaboración del modelo de edad.

\begin{tabular}{|c|c|c|c|c|c|c|c|}
\hline \multirow[t]{2}{*}{ Horizonte } & \multirow{2}{*}{$\begin{array}{l}\text { Código } \\
\text { laboratorio }\end{array}$} & \multirow{2}{*}{$\begin{array}{l}\text { Edad } \\
\text { convencional }\end{array}$} & \multicolumn{3}{|c|}{ Edad calibrada (AP) } & \multirow[t]{2}{*}{ Material fechado } & \multirow[t]{2}{*}{ Referencia } \\
\hline & & & de & $\mathrm{a}$ & mediana & & \\
\hline XOC16-II (0.82 m) & Beta 453194 & $7760 \pm 30$ & 8454 & 8595 & 8525 & Ostrácodos & $\begin{array}{l}\text { Reyes Corona } \\
(2017)\end{array}$ \\
\hline $\begin{array}{l}\text { Pómez Toluca Superior } \\
\text { (PTS) }\end{array}$ & A-9173 & $10445 \pm 95$ & 12621 & 12025 & 12329 & $\begin{array}{l}\text { Carbón dentro de flujo } \\
\text { piroclástico de PTS }\end{array}$ & $\begin{array}{l}\text { García-Palomo et } \\
\text { al. (2002) }\end{array}$ \\
\hline $\begin{array}{l}\text { Pómez Tutti Frutti } \\
\text { (PTF) }\end{array}$ & A- 8690 & $14065 \pm 500 / 470$ & 18340 & 15799 & 17066 & $\begin{array}{l}\text { Carbón dentro de la } \\
\text { unidad GT de la PTF. }\end{array}$ & $\begin{array}{l}\text { Sosa-Ceballos et } \\
\text { al. (2012) }\end{array}$ \\
\hline
\end{tabular}

1999; Sosa-Ceballos et al., 2012), por lo que se ha usado ampliamente como marcador estratigráfico en esta región. En el intervalo entre 1.10 y $1.25 \mathrm{~m}$ de profundidad, se encontró ceniza gris obscuro a gris claro, de grano grueso a fino, compuesta por vidrio vesiculado, cristales de plagioclasa, piroxeno, anfíbol y escasos líticos. Las características de los componentes juveniles y su posición estratigráfica (1-1.5 m por encima de la PTF), son comparables con las descritas en la cuenca de Chalco (Ortega-Guerrero et al. 2018). Esta capa de ceniza es correlacionable con la Pómez Toluca Superior (PTS), producto de una erupción pliniana del Nevado de Toluca, ocurrida hace ca. 12320 años cal AP (Bloomfield y Valastro, 1974; Macías et al., 1997; Capra et al., 2006; Arce et al., 2003). Los tres depósitos volcánicos restantes son cenizas de color gris obscuro localizados en los intervalos de $0.25-0.27,1.47-1.67$ y 2.02-2.06 $\mathrm{m}$ de profundidad, compuestas casi en su totalidad por vidrio negro y café obscuro, cuyas fuentes son desconocidas. Sin embargo, debido a su color y componente principal, los centros de emisión más probables se encontrarían en el vulcanismo monogenético de la sierra de Chichinautzin o de la sierra Santa Catarina.

Los sedimentos en los que dominan los componentes biogénicos están constituidos por un ooze de diatomeas entre 0.30-0.48 m, ylumaquelas de ostrácodos de $1 \mathrm{~cm}$ de espesor, a 1.73 y $0.82 \mathrm{~m}$ de profundidad.

La secuencia fue dividida en tres unidades de acuerdo con los componentes, (Figura 2). La unidad basal 3, de 2.47 a $1.10 \mathrm{~m}$ de profundidad, está constituida por limo y arcilla arenosa gris a pardo con abundantes restos de organismos silíceos; contiene cuatro de los cinco depósitos volcaniclásticos reconocidos: los depósitos de las pómez PTF y PTS, así como las cenizas denominadas en este trabajo $\mathrm{Cz}-2.06$ y Cz-1.67 (de acuerdo con su profundidad en la secuencia). La unidad 2, de 1.10 a $0.48 \mathrm{~m}$, está compuesta por limo gris obscuro con cantidades variables de arena y abundantes restos de carofitas (algas multicelulares que forman incrustaciones de calcita en sus superficies) y ostrácodos, y escasos cristales de calcita. La unidad 1 fue subdividida en las unidades $1 \mathrm{a}$ y $1 \mathrm{~b}$. La subunidad $1 \mathrm{~b}$, de $0.18 \mathrm{~m}$ de espesor, está compuesta por un ooze de diatomeas; la subunidad 1a, de $0.30 \mathrm{~m}$ de espesor, está constituida por limo arenoso gris obscuro que contiene abundantes restos silíceos, carbón y raíces de plantas, en los que se encuentra la ceniza $\mathrm{Cz}-0.27$ de $2 \mathrm{~cm}$ de espesor.

\section{Modelo de edad}

Se obtuvo un fechamiento ${ }^{14} \mathrm{C}$ AMS en un concentrado de ostrácodos a $0.82 \mathrm{~m}$ de profundidad (7760 \pm 30 años AP, Beta 453194). Para la elaboración del modelo se consideraron las edades calibradas de los marcadores estratigráficos reconocidos, la Pómez Tutti Frutti y la Pómez Toluca Superior, y la edad de ${ }^{14} \mathrm{C}$ (Tabla 1). La calibración de las edades se llevó a cabo con el programa OxCal 4.2 (Bronk Ramsey, 2009) utilizando la base de datos IntCal13 (Reimer et al., 2013). El modelo se elaboró a partir de la interpolación lineal de las edades calibradas, restando el espesor de los depósitos de tefras, ya que se considera instantáneo su depósito. La edad de la cima de la secuencia se estimó en ca. 5000 años cal AP, y la base en ca. 18000 años cal AP (Figura 3).
Las tasas de sedimentación calculadas entre los horizontes de edad conocida varían entre 0.08 y 0.23 mm/año (Albarrán-Santos, 2018).

\section{Parámetros magnéticos y geoquímicos}

Las propiedades magnéticas y geoquímicas coinciden cercanamente con las unidades litoestratigráficas, por lo que se describen de acuerdo con las mismas.

\section{Unidad 3}

La mineralogía magnética de los depósitos volcaniclásticos, de acuerdo con los análisis $\kappa-\mathrm{T}$ (Tabla 2), está dominada por Ti-magnetitas con diversos contenidos de Ti (Tc: $320,430,450,560^{\circ} \mathrm{C}$ ). En general, estos depósitos volcaniclásicos presentan las más altas concentraciones de minerales ferrimagnéticos (alta $\chi, \chi_{\text {MRA }} y \mathrm{Mr}$ ), de relativamente alta coercitividad ( $>$ Hcr y MRID, $<S_{300}$ ), con una mezcla de tamaños multidominio $(\mathrm{MD},>0.2 \mu \mathrm{m})$ y ultrafinos superparamagnéticos $(\mathrm{SP},<0.03$ $\mu \mathrm{m})$ (Figura 4). El depósito de la PTS difiere de estas características, ya que presenta baja concentración de ferrimagnéticos, debido a su composición dacítica (Arce et al., 2003) y bajas coercitividades. Las diferencias en las propiedades magnéticas de estos depósitos se deben a varias razones, entre otras la composición de los magmas, los procesos de cristalización y la alteración a alta temperatura.

Los sedimentos entre la PTF y la ceniza Cz-1.67 m presentan mayor concentración de minerales magnéticos $(>\chi, \mathrm{Mr})$, con una mezcla de tamaños MD (<MRA/MRI) y SP $\left(>\chi_{\mathrm{fd} \%}\right)$ y de relativamente mayor dureza ( $>$ Hcr y MRID, $<\mathrm{S}_{300}$ ), que aquéllos en la base y la cima de esta unidad (Figura 4). De acuerdo con las curvas $\kappa-\mathrm{T}$, el limo pardo gris de esta unidad $(1.72 \mathrm{~m})$, presenta una mineralogía dominada por Ti-

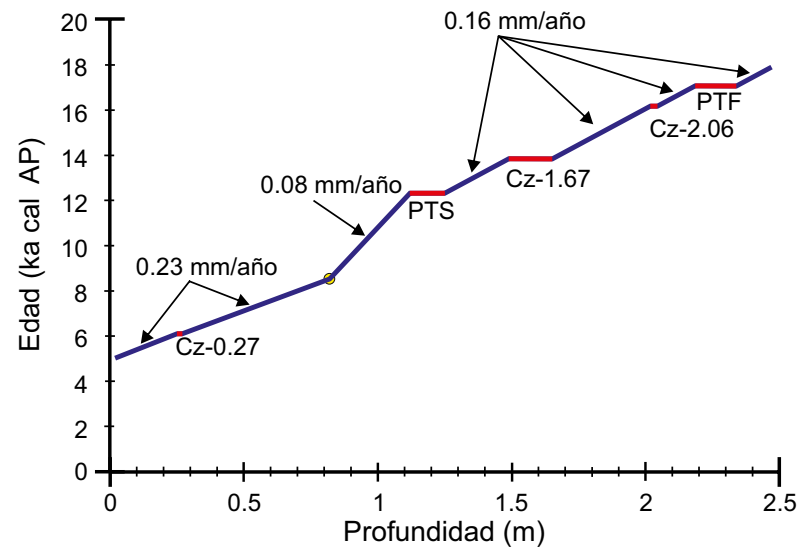

Figura 3. Modelo de edad del sondeo XOC16-II. En línea roja se marca la posición de los cinco depósitos de tefra reconocidos (PTF, Cz-2.06, Cz-1.67, PTS, Cz-0.27). El círculo amarillo indica la posición del horizonte de ostrácodos fechado por ${ }^{14} \mathrm{C}$. Se indican las tasas de sedimentación para cada intervalo de edad conocida, asumiendo un depósito instantáneo para la tefra. 
Tabla 2. Temperaturas de Curie calculadas en los análisis к-T.

\begin{tabular}{lccc}
\hline Unidad & $\begin{array}{c}\text { Profundidad } \\
(\mathrm{m})\end{array}$ & $\mathrm{T}_{\mathrm{C}}\left(\mathrm{T}_{\mathrm{N}}\right)$ & Mineralogía \\
\hline 1a & 0.02 & $80,430, \sim 580$ & Goethita, TM25, Magnetita \\
& 0.12 & $90,440,625$ & Goethita, TM25, Hematita \\
& 0.22 & $80,440, \sim 580$ & Goethita, TM25, Magnetita \\
3 & 1.36 & 140,510 & TM65, TM10 \\
& 1.69 & $\sim 100,430,650$ & Goethita, TM25, Magnetita, \\
& 1.72 & $\sim 580$ & Hematita \\
& 1.73 & 430 & TM25 \\
Tefras & Cz-0.27 & 440,660 & TM70-75 \\
& PTS & 320,560 & TM40, Magnetita \\
& Cz-1.67 & 430,630 & TM25, Hematita \\
& Cz-2.06 & 450 & TM20 \\
& PTF & 85,480 & TM70, TM20 \\
\hline
\end{tabular}

$\mathrm{T}_{\mathrm{C}}\left(\mathrm{T}_{\mathrm{N}}\right)$ : temperatura de Curie/Neel

magnetitas Tc $\sim 430$ (Tabla 2; Figura 5a). En el limo arenoso (1.69 m), el decremento a $100^{\circ} \mathrm{C}$ en la curva $\kappa-T$ indica la presencia de goethita además de Ti-magnetita y magnetita (Figura 5a); aunque en la curva de adquisición de MRI presenta una dureza magnética menor que aquella del limo pardo gris (1.72 m) (Figura $5 b$ ).

Los análisis de distribución de coercitividades para esta unidad revelan que la magnetización remanente es portada principalmente por dos componentes de baja coercitividad (CBC; $\mu_{0} \mathrm{Hc}<200 \mathrm{mT}$ ) (Material Suplementario Figura S1a, Material Suplementario Tabla S2), y en el limo arenoso $(1.69 \mathrm{~m})$ adicionalmente por una componente de alta coercitividad (CAC; $\mu_{0} \mathrm{Hc} 253 \mathrm{mT}$ ). La CBC más suave y abundante (47-71\%) está caracterizada por $\mu_{0} \mathrm{Hc}$ de 55 a $58 \mathrm{mT}$ y un parámetro de dispersión (DP) alrededor de 0.42 . La CBC menos suave presenta $\mu_{0} \mathrm{Hc}$ entre 95 y $184 \mathrm{mT}$, y un DP de 0.23 a 0.32. Estas componentes suaves presentan valores más altos que los reportados para los componentes detríticos $\left(\mu_{0} \mathrm{Hc} \sim 30 \mathrm{mT}\right)$ y para los magnetosomas de coercitividad baja $\left(\mu_{0} \mathrm{Hc} \sim 45 \mathrm{mT}\right)$ y alta $\left(\mu_{0} \mathrm{Hc} \sim 70 \mathrm{mT}\right)($ Egli, 2004), identificados como biogénicos suaves y biogénicos duros, respectivamente. De acuerdo con las Tc, la CBC suave puede corresponder a Ti-magnetita MD detrítica, y la oxidación parcial de la misma o la presencia de maghemita causaría el aumento en la coercitividad (Liu et al., 2002, 2007; Özdemir and Dunlop, 2014). Esta interpretación es consistente con los valores relativamente altos de $\chi y$ Mr. La $\chi_{\mathrm{fd}} \%$ es comúnmente usada como un indicador de magnetita o maghemita SP, y es claro el aporte de una componente SP entre 1.40 y $2.0 \mathrm{~m}$ en esta unidad. La componente $\mathrm{CBC}$ menos suave, alrededor de $170 \mathrm{mT}$, puede representar hematita ultrafina de baja coercitividad (Liu et al., 2002, 2007). La CAC presenta $\mu_{0} \mathrm{Hc}$ de $253 \mathrm{mT}$ y DP de 0.2, que corresponde a hematita (Egli, 2004).

Aunque la presencia de goethita es sugerida en las curvas $\kappa-T$, no es posible establecer una conclusión definitiva sobre la presencia de ésta en el análisis de coercitividad ya que el campo de saturación utilizado (1 T), es demasiado bajo para magnetizarla de manera eficiente.

En concordancia con los parámetros magnéticos, en la unidad 3 se presentan las concentraciones más elevadas de elementos "detríticos" como $\mathrm{Ti}$ y $\mathrm{Fe}$; así como valores relativamente bajos $\mathrm{Ca}, \mathrm{Ca} / \mathrm{Ti}$ y Si/Ti, y moderados Fe/Ti (Figura 6). El contenido de carbón tanto orgánico (COT) como inorgánico (CIT) es muy bajo, excepto alrededor de $1.72 \mathrm{~m}$, que corresponde a una lumaquela de ostrácodos. El cociente Corg/N muestra valores intermedios en la base $(\sim 11)$, que entre $2.05 \mathrm{y}$ $1.85 \mathrm{~m}$ de profundidad disminuyen a 7 , y hacia la cima aumenta hasta 17; justo debajo de la PTS (1.34-1.25 m) disminuyen a $\sim 14$.

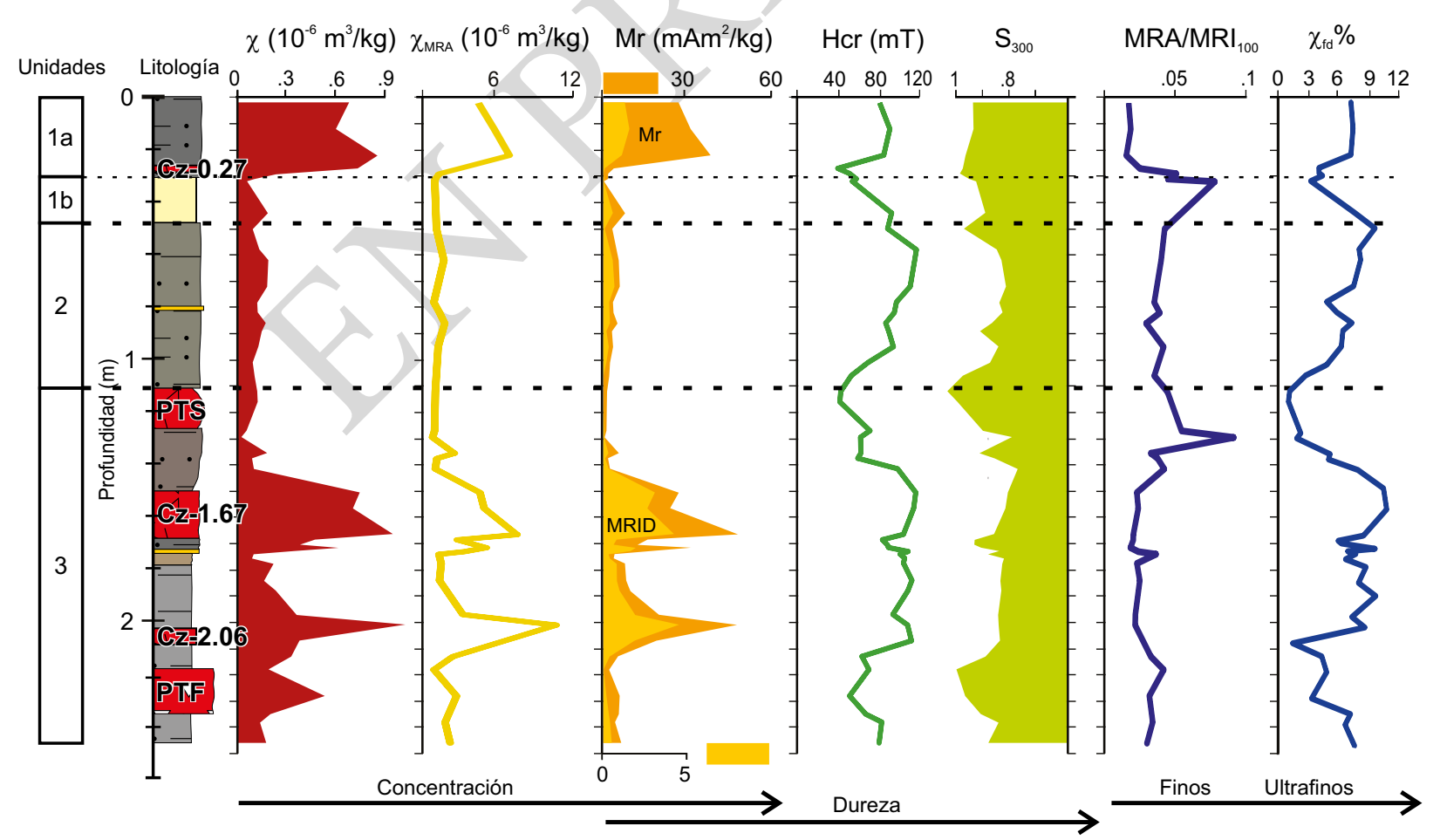

Figura 4. Parámetros magnéticos. Los indicadores de concentración de minerales ferrimagnéticos son $\chi, \chi_{\mathrm{MRA}}, \mathrm{y}$ Mr (magnetización remanente). La abundancia de minerales de alta coercitividad (o "duros"), hematita/goethita, es inferida por MRID (magnetización remanente isotermal dura), Hcr (coercitividad remanente) y el cociente $\mathrm{S}_{300}$. La relación MRA/MRI ${ }_{100}$ es una medida de la abundancia de minerales de tamaño fino de dominio sencillo y $\chi$ fd\% es indicador de la abundancia de minerales ultrafinos superparamagnéticos (ver Material Suplementario Tabla S1). 

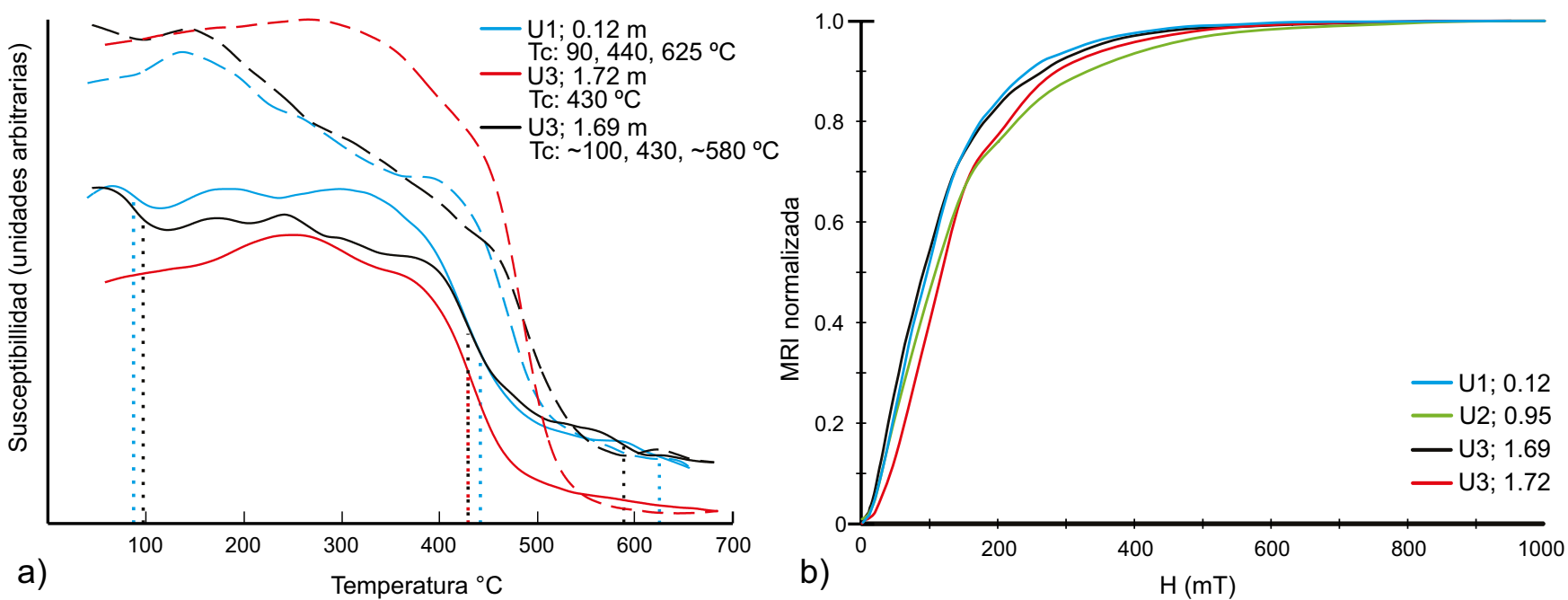

Figura 5. a) Curvas $\kappa-\mathrm{T}$ de muestras selectas. La curva sólida es el calentamiento, la curva discontinua es el enfriamiento, las líneas punteadas señalan las temperaturas de Curie estimadas. Las curvas de enfriamiento señalan la alteración, a alta temperatura, a fases más estables (magnetita) en todas las muestras. b) Las curvas de adquisición de MRI indican la presencia de minerales magnéticos relativamente suaves (Ti-magnetita MD) en las unidades 1 y 3 , y duros en la unidad 2 (goethita/hematita).

\section{Unidad 2}

En ésta se presenta la más baja concentración de minerales ferrimagnéticos (bajas $\chi$ y Mr), por lo que no fue posible obtener curvas confiables de $\kappa$ en función de la temperatura. Tanto los valores altos de Hcr y bajos de $\mathrm{S}_{300}$ (Figura 4), como las pendientes en las curvas de adquisición de MRI (Figura 5b, muestra 0.95), indican la contribución significativa de minerales de alta dureza (hematita/goethita) en los sedimentos. El relativo aumento en la relación MRA/MRI $\mathrm{M}_{100}$ sugiere el aumento en la concentración de partículas finas dominio sencillo (DS, $<0.2 \mu \mathrm{m})$, así como de partículas $\mathrm{SP}\left(>\chi_{\mathrm{fd} \%}\right)$. Los análisis de distribución de coercitividades indican dos componentes de baja coercitividad $(<200 \mathrm{mT})$, una menos abundante $(22-32 \%)$ con $\mu_{0} \mathrm{Hc} 26$ a $37 \mathrm{mT}$ y DP de 0.24 a 0.34 , y otra más abundante (63-69\%) de $\mu_{0} \mathrm{Hc}$ de 118 a $147 \mathrm{mT}$ y DP 0.29 a 0.34 (Tabla S2; Material Suplementario Figura $1 b$ ). Existe también una CAC de $\mu_{0} \mathrm{Hc} \sim 350 \mathrm{mT}$ y DP 0.21 en la muestra $0.62 \mathrm{~m}$, que es mayor que lo reportado por Egli (2004) para la hematita $(200 \mathrm{mT})$. La componente más suave semeja a la componente detrítica reportada por Egli (2004). Es posible que la componente de

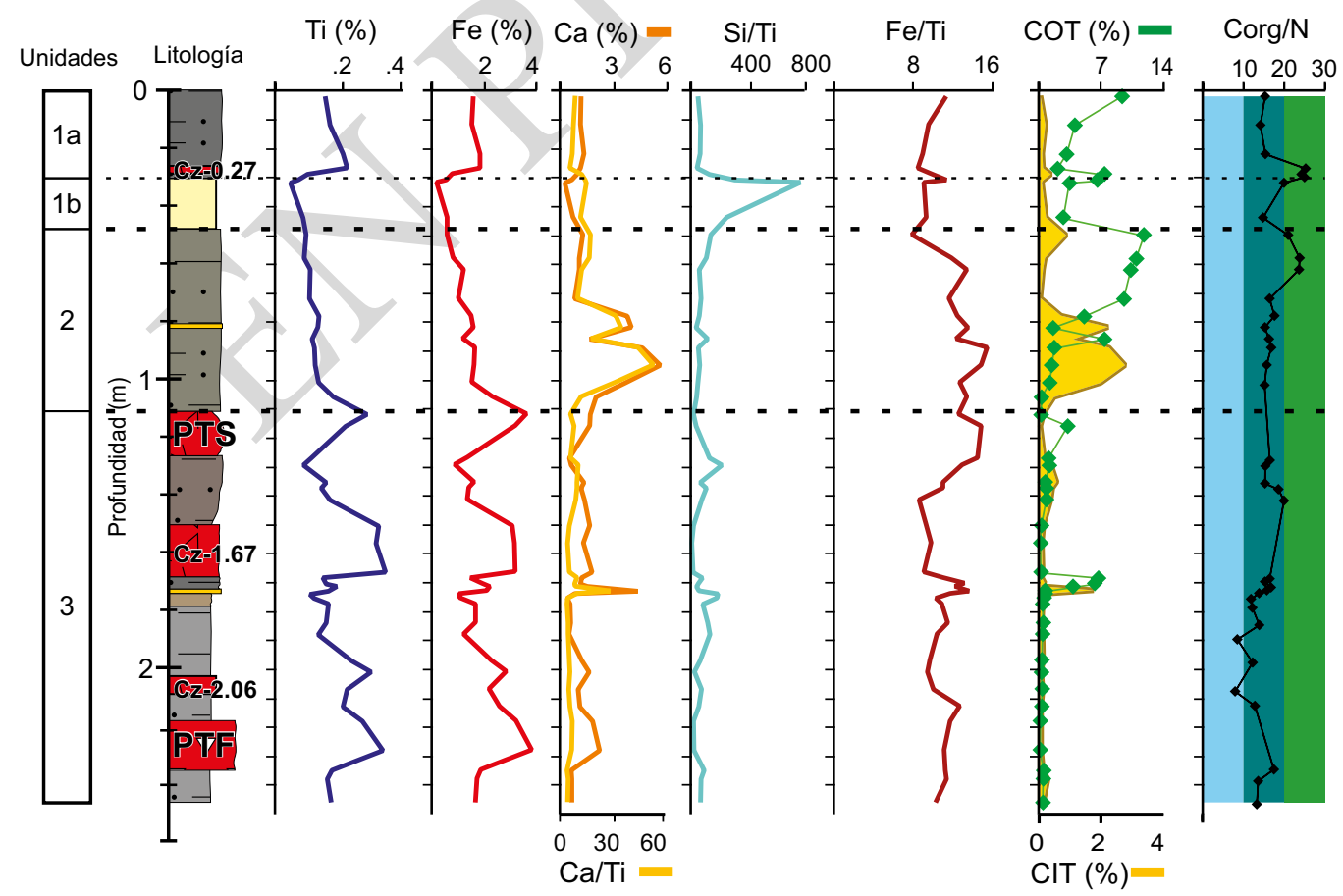

Figura 6. Parámetros geoquímicos. Ti y Fe son indicadores de aporte de detritos. El Ca puede ser de origen detrítico o autigénico, por lo que la relación Ca/Ti se utiliza para discriminar el Ca autigénico. Si/Ti es una medida del Si biogénico (mayormente diatomeas). Fe/Ti representa la re-precipitación de Fe. COT: carbono orgánico total; CIT: carbono inorgánico total. La relación Corg (carbono orgánico)/ $\mathrm{N}$ se utiliza para discriminar el origen de la materia orgánica: acuática si es $<10 \%$, terrestre si es $>20 \%$ y de origen mixto entre ambos porcentajes. 
$\mu_{0} \mathrm{Hc}$ intermedia (118-147 $\mathrm{mT}$ ) represente la transformación parcial de minerales ferrimagnéticos de baja coercitividad a hematita, que en intervalos alcanza su completa transformación, donde $\mu_{0} \mathrm{Hc}>300 \mathrm{mT}$. Esta interpretación se sustenta en los bajos valores de $\chi$ y $\mathrm{Mr}$, que señalan una disminución en la contribución de las fases ferrimagnéticas. Esta idea se discute más adelante.

Los parámetros geoquímicos muestran bajas concentraciones de Ti y Fe a lo largo de esta unidad, así como valores relativamente altos del cociente $\mathrm{Fe} / \mathrm{Ti}$. La parte inferior (1.0-0.7 m profundidad), muestra los mayores valores de la relación $\mathrm{Ca} / \mathrm{Ti}$ registrados en toda la secuencia, que coinciden con los valores más altos de CIT. El cociente Corg/N se mantiene entre 13-18. Por arriba de $0.70 \mathrm{~m}$ de profundidad, disminuyen $\mathrm{Ca} / \mathrm{Ti}$ y CIT, y aumentan COT y Corg/N (Figura 6).

\section{Unidad 1}

En la unidad 1b, en el ooze de diatomeas, la concentración de minerales magnéticos es baja, aumenta la concentración de minerales DS y disminuye la coercitividad y la fracción SP (Figura 4). En la subunidad la se presenta la mayor concentración de minerales ferrimagnéticos en los sedimentos lacustres (altas $\chi, \chi_{\text {MRA }} y \mathrm{Mr}$ ). Las coercitividades son relativamente suaves ( $\mathrm{Hcr} \sim 90 \mathrm{mT}, \mathrm{S}_{300}$ $>0.9$ ) con baja concentración de tamaños DS (<MRA/MRI ${ }_{100}$ ) aunque relativamente alta concentración de granos ultrafinos SP $\left(>\chi_{\mathrm{fd} \%}\right)$ (Figura 4). Las curvas $\kappa-\mathrm{T}$ en esta subunidad 1a indican la presencia de una mezcla de minerales variada: goethita $\left(\mathrm{Tc} 100{ }^{\circ} \mathrm{C}\right)$, Ti-magnetitas $\left(\mathrm{Tc} 420-530^{\circ} \mathrm{C}\right)$, magnetita pura $\left(\mathrm{Tc} \sim 580^{\circ} \mathrm{C}\right)$ y hematita (Tc $\sim 625^{\circ} \mathrm{C}$ ) (Figura 5a, muestra 0.12). El análisis de la distribución de coercitividades revela que en esta subunidad la magnetización remanente es aportada principalmente por tres componentes, todas $\mu_{0} \mathrm{Hc}<200 \mathrm{mT}$ y con abundancias relativas similares (Material Suplementario Figura S1c y Tabla S2). La componente más suave presenta $\mu_{0} \mathrm{Hc}$ de $35 \mathrm{mT}$ y DP de 0.23 , y corresponde a Ti-magnetita detrítica. La componente intermedia presenta $\mu_{0} \mathrm{Hc}$ de $99 \mathrm{mT}$ y DP 0.15 , y la componente menos suave presenta $\mu_{0} \mathrm{Hc}$ de $154 \mathrm{mT}$ y DP $\sim 0.21$. Es posible que la componente intermedia $(99 \mathrm{mT})$ corresponda a maghemita SP y/o a magnetofósiles de alta coercitividad parcialmente oxidados, interpretación que se apoya en el aumento de partículas SP $y$ en el incremento en los indicadores de minerales ferrimagnéticos $(\chi$, $\chi_{\text {MRA }}$ Y Mr), así como la presencia de magnetita de acuerdo con las Tc. La componente de mayor coercitividad puede corresponder a hematita ultrafina de baja coercitividad.

En la subunidad $1 \mathrm{~b}$ se encuentra la más alta relación $\mathrm{Si} / \mathrm{Ti}$, en tanto que se mantienen con valores bajos el resto de los elementos y cocientes. En afinidad con los parámetros magnéticos de concentración, el Ti y Fe (y en menor proporción $\mathrm{Fe} / \mathrm{Ti}$ ) presentan valores altos en la subunidad la, y una reducción en los restantes elementos y cocientes. Tanto COT como CIT se mantienen bajos, aunque en la base hay un aumento significativo en COT y en la relación Corg/N (Figura 6).

\section{Análisis de diatomeas}

Se identificaron un total de 22 especies de diatomeas de las cuales 12 tuvieron abundancias mayores al $10 \%$ (Figura 7). Los cambios en las asociaciones de estas diatomeas permiten identificar tres zonas que correlacionan estrechamente con las unidades estratigráficas, por lo que la descripción de las asociaciones de diatomeas se ajustará con las unidades ya descritas.

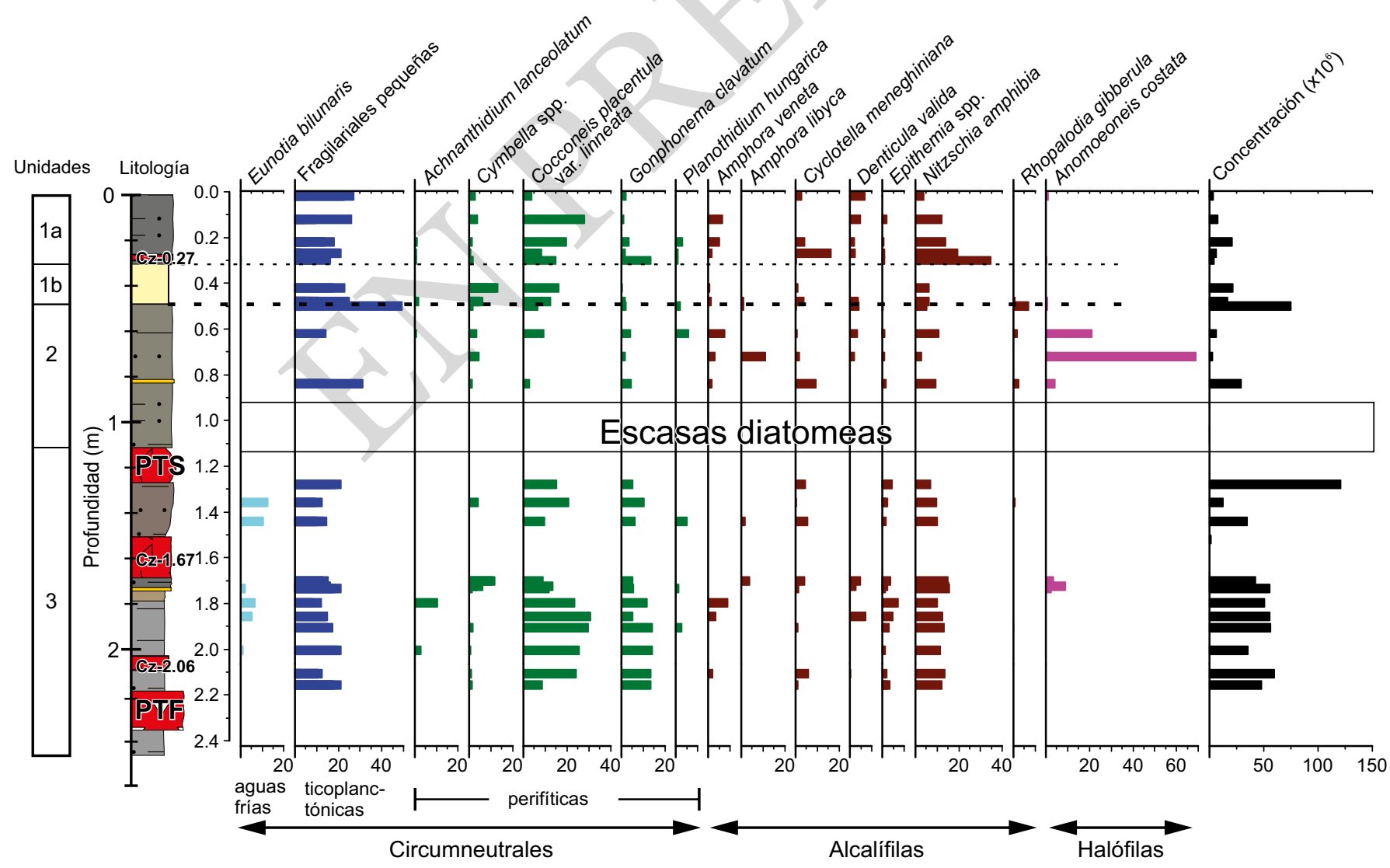

Figura 7. Abundancia de diatomeas. Las especies están agrupadas de acuerdo con su hábitat: circumneutrales, alcalífilas y halófilas. La concentración en valvas por gramo de sedimento seco se muestra a la derecha. 


\section{Unidad 3}

Esta zona muestra concentraciones de diatomeas que van entre 35 y $50 \times 10^{6} \mathrm{v} / g s s$, excepto en los horizontes que corresponden con material volcánico y en la muestra $1.2 \mathrm{~m}$ que tiene una abundancia de $>100 \times 10^{6} \mathrm{v} /$ gss. El conjunto de diatomeas está dominado por variedades de ambientes circumneutrales entre las que destacan la especie epifita Cocconeis placentula var. lineata y un conjunto de pequeñas diatomeas arrafidales consideradas como ticoplanctónicas, que incluyen a Pseudostaurosira brevistriata, Staurosira venter y Staurosirella pinnata. Otras diatomeas presentes en menores proporciones son Nitzschia amphibia, Gompnonema clavatum y unos cuantos ejemplares de la especie halófila Anomoeoneis costata en la muestra $1.7 \mathrm{~m}$. En particular llama la atención la presencia en este conjunto de Eunotia bilunaris, una especie que puede considerarse indicadora de aguas relativamente frías.

\section{Unidad 2}

Esta zona muestra bajas concentraciones de diatomeas, que en general son $<1 \times 10^{6} \mathrm{v} /$ gss por debajo de $0.55 \mathrm{~m}$, con un aumento por arriba de esta profundidad, especialmente en la muestra $0.5 \mathrm{~m}$ que tiene valores $>70 \times 10^{6} \mathrm{v} /$ gss. Entre 0.86 y $0.55 \mathrm{~m}$ se observa una reducción en la abundancia de C. placentula var. lineata y las pequeñas arrafidales, mientras que aumentan inicialmente algunas especies alcalófilas como Cyclotella meneghiniana y Planothidium lanceolatum, y posteriormente la especie halófila Anomoeoneis costata. Entre 0.95 y $1.15 \mathrm{~m}$ las diatomeas son muy escasas.

\section{Unidad 1}

En la subunidad $1 \mathrm{~b}$ se registra un nuevo aumento en la abundancia de las pequeñas arrafidales y de C. placentula var. linneata, que coincide con el aumento en la concentración de diatomeas. La subunidad la presenta concentraciones de diatomeas intermedias a bajas, con valores que oscilan entre 20 y $4 \times 10^{6} \mathrm{v} /$ gss. En cuanto a los conjuntos de diatomeas, vuelven a ser muy similares a los presentes en la Unidad 3, si bien con un máximo de abundancia inicial de la especie alcalífila Nitzschia amphibia y, en general, con abundancias muy bajas de Gomphonema clavatum y sin la presencia de Eunotia bilunaris.

\section{DISCUSIÓN}

El modelo de edad permite establecer los límites temporales de las unidades estratigráficas. De acuerdo con éste, la Unidad 3 abarca de ca. 18000 a 12320 años cal AP, la unidad 2 de 12320 a 7100 años cal AP y la unidad 1 entre 7100 y 5000 años cal AP. Estos intervalos corresponden de manera cercana a la deglaciación, el Holoceno temprano y el Holoceno medio, respectivamente. Las características de los sedimentos durante la deglaciación (18000 a 11700 años cal AP; Clark et al., 2009) muestran el control de los depósitos volcánicos en la sedimentación. Las fuentes de tefra han sido sólo reconocidas para la PTF (del Popocatépetl) y la PTS (del Nevado de Toluca). El depósito de tefra Cz-2.06 tiene una edad aproximada de 16200 años cal AP, y podría correlacionar con los depósitos de ceniza gris de origen desconocido encontrados sobre la PTF en la porción central de la sierra Chichinautzin (Siebe et al., 2005). Los índices de color (composición intermedia), de los horizontes de tefra Cz-1.67 y Cz-0.27 sugieren que son producto de la sierra Chichinautzin. Con el propósito de observar con mayor claridad las variaciones paleoambientales, en la síntesis de indicadores de la Figura 8 se han omitido los valores correspondientes a las cenizas volcánicas, y se han graficado los indicadores magnéticos y no magnéticos más ilustrativos en escala temporal.

\section{Deglaciación (18000-11700 años cal AP).}

$\mathrm{Al}$ inicio de la deglaciación, antes del depósito de la PTF (18000 -17000 años cal AP), existió un aporte limitado de sedimentos a la cuenca por corrientes superficiales, como se observa en $x y$ Ti (Figura 8). La fracción arenosa de los sedimentos indica un ambiente litoral para el sitio de estudio, y el escaso contenido de materia orgánica, de

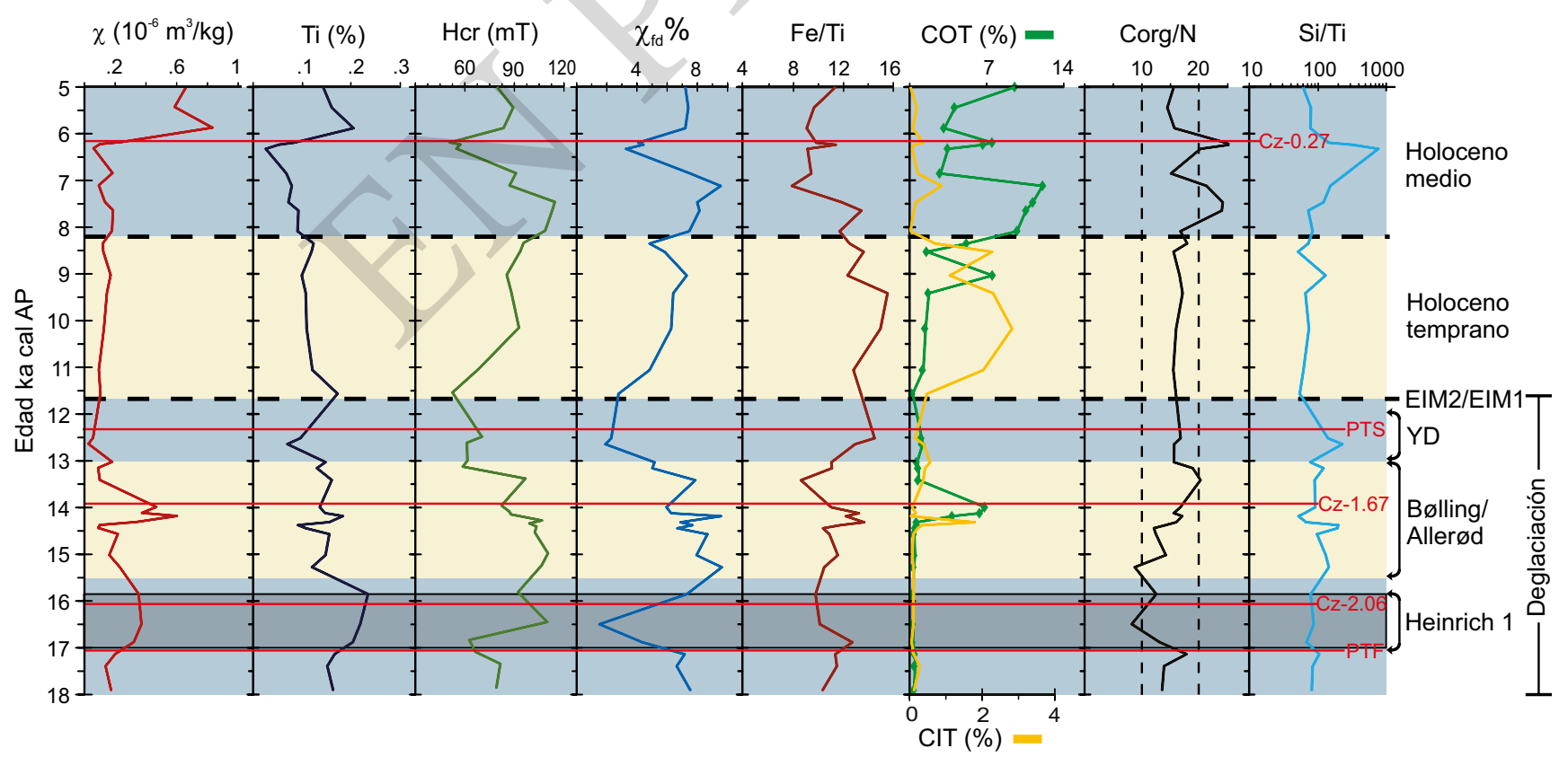

Figura 8. Registros paleoclimáticos de la cuenca de Xochimilco entre 18000 y 5000 años cal AP. Las franjas azules señalan los periodos relativamente fríos, y las amarillas los relativamente más cálidos. Se indican las temporalidades de los eventos: Heinrich 1 (seco y frío, 17000-15800 años cal AP); Bølling/Allerød (intervalo relativamente cálido, B/A, 15500-13000 años cal AP); Younger Dryas (YD, 13000-12000 años cal AP, intervalo frío); EIM2/EIM1 (transición entre los estadíos isotópicos marinos 2 a 1); el Holoceno temprano y el Holoceno medio. 
origen mixto, sugiere ausencia de vegetación palustre significativa y un limitado desarrollo de la vegetación terrestre. La escasez de materia orgánica favoreció la existencia de condiciones óxicas en el ambiente de depósito. En estas condiciones, la mineralogía magnética estuvo controlada por flujos de sedimentos externos, fluviales o eólicos. Durante este intervalo, la dureza magnética moderada y los bajos MRA/MRI (Figura 4), indican que la mineralogía magnética corresponde a Timagnetitas parcialmente oxidadas o maghemitas, de tamaño MD con una contribución moderada de tamaños SP proveniente de los suelos de la cuenca (Figura 9).

Durante el evento seco y frío Heinrich 1 (H1, 17000-15800 años cal AP; Heinrich, 1988), la disponibilidad de productos volcánicos de caída (de la PTF y Cz-2.06), y la contracción de la vegetación terrestre señalada por < Corg/N, favorecieron la erosión superficial. La mineralogía magnética fue dominada por Ti-magnetitas parcialmente oxidadas, detríticas, en tanto que la formación de hematita, derivada de la oxidación de minerales de Fe, fue limitada, lo que es congruente con un restringido desarrollo de los suelos. Las diatomeas indican la existencia de un lago somero de agua dulce y la presencia de Eunotia bilunaris sugiere aguas relativamente frías comparadas con las actuales. Lo anterior indica que, durante la deglaciación, hubo disponibilidad de materiales no consolidados producto del volcanismo y que existió un balance fluctuante pero que se mantuvo positivo en la relación precipitación/evaporación, lo que favoreció la sedimentación clástica en un lago somero de agua dulce y relativamente fría (Figura 9).

Durante el intervalo posterior relativamente cálido Bølling/Allerød (B/A, 15500-13000 años cal AP), se registra un aumento progresivo de materia orgánica terrestre (Figura 8). En la fase inicial templada (Bølling, ca. 15500-14300 años cal AP), el aporte de detritos al lago fue limitado $(<\chi)$, el contenido de COT se mantuvo bajo y dominó la materia orgánica de origen acuático. La mineralogía magnética registra Ti-magnetitas detríticas parcialmente oxidadas y minerales de tamaño SP, probablemente maghemita pedogénica. Los granos de magnetita/ maghemita ultrafina se producen por procesos pedogénicos en suelos bien drenados con materia orgánica y $\mathrm{Fe}$, con periodos húmedos (producción de $\mathrm{Fe}^{2+}$ ) que alternan con periodos secos (precipitación de óxidos $\mathrm{Fe}^{2+} / \mathrm{Fe}^{3+}$ ) (Maher y Thompson, 1995). Justo al inicio de la fase cálida (Allerød), se registró un pico de CIT (y Ca/Ti) hacia 14300 años cal AP, que coincide con un aumento en A. costata, sugiriendo condiciones lacustres que brevemente mostraron mayor salinidad. Posteriormente, el incremento en $\chi$, COT y Corg/N, indican un mayor aporte de detritos al lago, mayor productividad biogénica y la expansión de la vegetación terrestre, que en conjunto apuntan a condiciones más húmedas (Figura 9). El aumento de $\chi_{\mathrm{fd}} \%$, Hcr y Fe/Ti (que indica la re-precipitación de Fe) (Figura 8), es consistente con el incremento en la formación de minerales pedogénicos, maghemita o magnetita parcialmente oxidadas, de tamaño SP, así como hematita o goethita detrítica $\left(\mu_{0} \mathrm{Hc} 253\right)$. La formación de goethita es favorecida en suelos húmedos templados que sólo rara vez experimentan prolongados intervalos de sequía. En contraste, la hematita es más abundante en suelos con frecuentes episodios de sequías prolongadas (Kampf y Schwertmann, 1983; Cornell y Schwertmann, 2003).

El intervalo frío del Younger Dryas (YD, 13000-12000 años cal $\mathrm{AP})$, marcó un cambio respecto a las condiciones ambientales previas: disminuyó el aporte de detritos $(<\chi, \mathrm{Ti}, \mathrm{Hcr})$ y la formación de minerales magnéticos duros, como hematita y goethita $(<\mathrm{Hcr})$ (Figura 8). La vegetación terrestre se contrajo y aumentó la concentración de diatomeas ( $y$, en general, del sílice biogénico, $>\mathrm{Si} / \mathrm{Ti}$ ), que señalan la existencia de un lago somero de agua dulce y fría. Estas características indican la existencia de condiciones secas, que restringieron el aporte de detritos al lago y que limitaron el intemperismo, lo que resultó en una menor formación de óxidos de Fe.

\section{Holoceno temprano}

La transición de la deglaciación al Holoceno temprano (desde 11700 años cal AP hasta ca. 8200 años cal AP), está marcada por un cambio en los componentes sedimentarios, en los parámetros geoquímicos y en las propiedades magnéticas. La fracción clástica del tamaño del limo continuó siendo dominante, con arena diseminada y dispuesta en bandas; sin embargo, aparecieron abundantes restos de carofitas y ostrácodos, así como carbón y localmente, cristales de calcita. Los indicadores de erosión señalan la disminución en el aporte de detritos por escorrentías, el contenido de COT es bajo y el incremento en CIT es consistente con la abundancia de materiales calcáreos (Figura 8). La asociación de diatomeas indica ambientes alcalinos y salobres, que apuntan a una disminución en el nivel lacustre. En conjunto, estas características reflejan condiciones de alta evaporación, con la consecuente reducción del cuerpo lacustre cuyas aguas se concentran y permiten el desarrollo de formas calcáreas y la precipitación de calcita. La abundancia de fragmentos de carbón, derivados de incendios, refuerza la interpretación de condiciones relativamente secas durante este intervalo (Figura 9).

La separación de componentes magnéticas indica una componente con $\mu_{0} \mathrm{Hc} \sim 147$ a $350 \mathrm{mT}$, que se interpreta como una transformación parcial a total de minerales ferrimagnéticos de baja coercitividad a hematita y/o goethita. El aumento en la relación Fe/Ti indica la reprecipitación de $\mathrm{Fe}$, y los granos SP sugieren una componente pedogénica. Bajo las condiciones secas que se infieren de los parámetros no magnéticos, la formación de hematita es más probable que la de goethita. Este intervalo coincide con el máximo de insolación de verano para el hemisferio norte que ocurrió alrededor de 10000 años cal AP, y que es la edad del pico de CIT en la secuencia.

Hacia los 9500 años cal AP se registra un retorno a condiciones menos secas, con la disminución en CIT y un aumento de COT (Figura 8). Las propiedades magnéticas señalan una disminución en los granos SP aunque, las coercitividades y las concentraciones se mantienen sin cambio significativo respecto a la etapa anterior. Sin embargo, esta tendencia es interrumpida hacia 8520 años cal AP, cuando ocurre un breve retorno a condiciones de sequía como lo sugieren el aumento en CIT (y de manera menos marcada en Fe/Ti), la disminución en COT y la presencia de diatomeas halófilas. Este abrupto cambio puede corresponder al episodio de enfriamiento ocurrido hacia 8200 años cal AP, en el cual la catastrófica liberación de las aguas de los lagos glaciales Agassiz y Ojibway al Atlántico del Norte cortó la circulación de agua profunda de este océano y su consecuente transporte de calor (Barber et al., 1999). La discrepancia en las edades es posiblemente debido a las limitaciones de nuestro modelo de edad.

\section{Holoceno medio}

A partir de 8200 años cal AP y durante el Holoceno medio (hasta ca. 7100 años cal AP), se registra un cambio drástico en los indicadores geoquímicos. Este es el intervalo con mayor contenido de COT y los cocientes más altos de Corg/ $\mathrm{N}$, que indican la máxima expansión de la vegetación terrestre (Figura 8 ). También se registra un aumento de sílice biogénico, y disminución del contenido de carofitas y ostrácodos, lo que concuerda con la disminución en CIT. Los indicadores de erosión presentan en conjunto los valores más bajos de toda la secuencia. Los parámetros magnéticos señalan la presencia de granos SP y componentes de las mayores coercitividades encontradas $\left(\mu_{0} \mathrm{Hc}\right.$ 350), además de la fracción detrítica de baja coercitividad. Para este intervalo, se infiere el desarrollo de suelos saturados con una extensa cubierta vegetal que redujo la erosión superficial, y en los cuales ocurrió la formación de goethita (Figura 9).

Entre 7100 a 5000 años cal AP, las especies de diatomeas circumneutrales volvieron a ser dominantes, indicando una condición de 

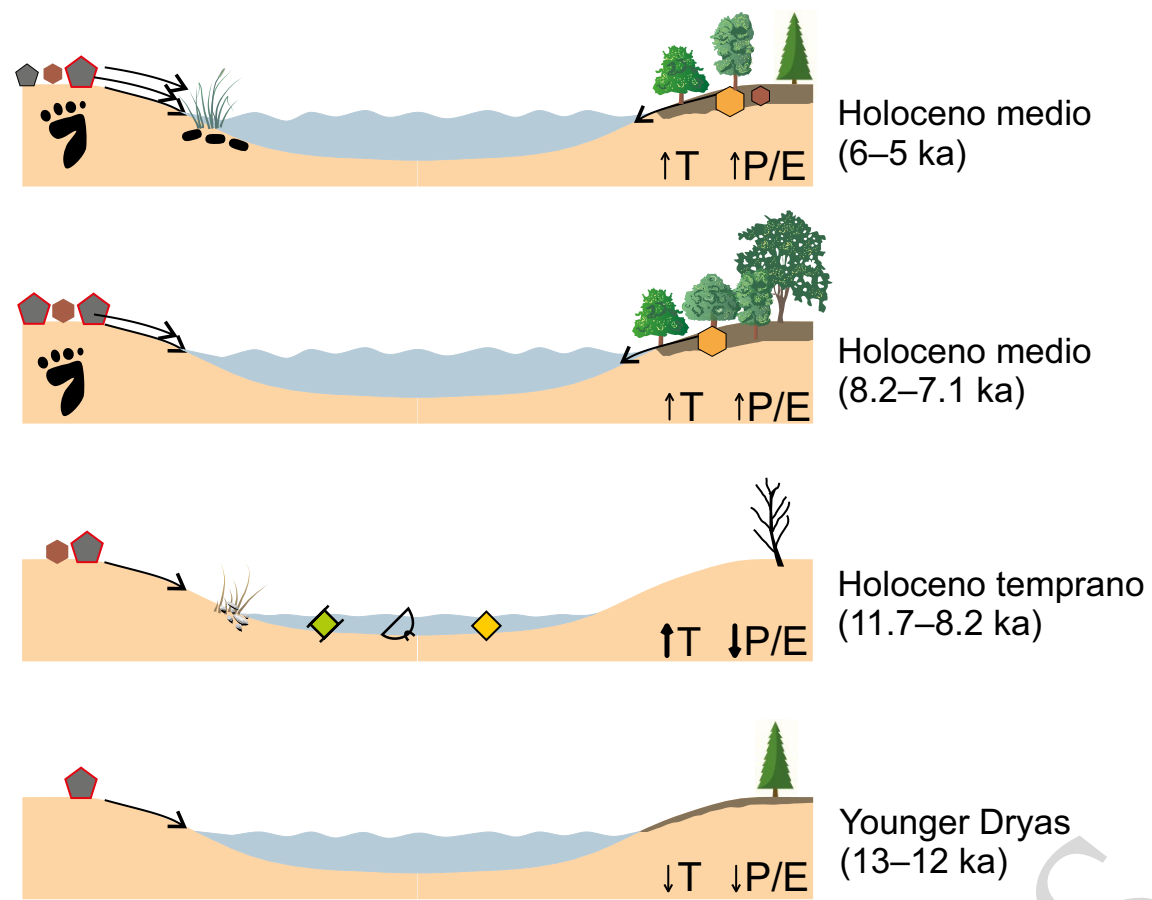

Ti-magnetita oxidada/maghemita

Magnetita/maghemita SP

Hematita

Goethita

Hematita ultrafina

Magnetosomas

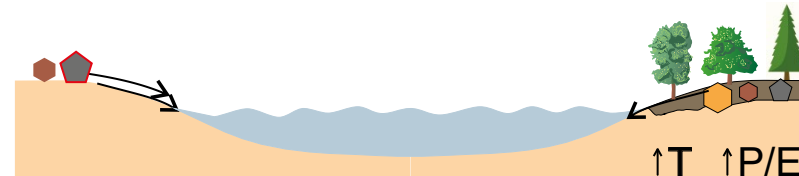

Bølling/Allerød

$\diamond$ Calcita (15.5-13 ka)

$Q$ Ostrácodos

Carofitas
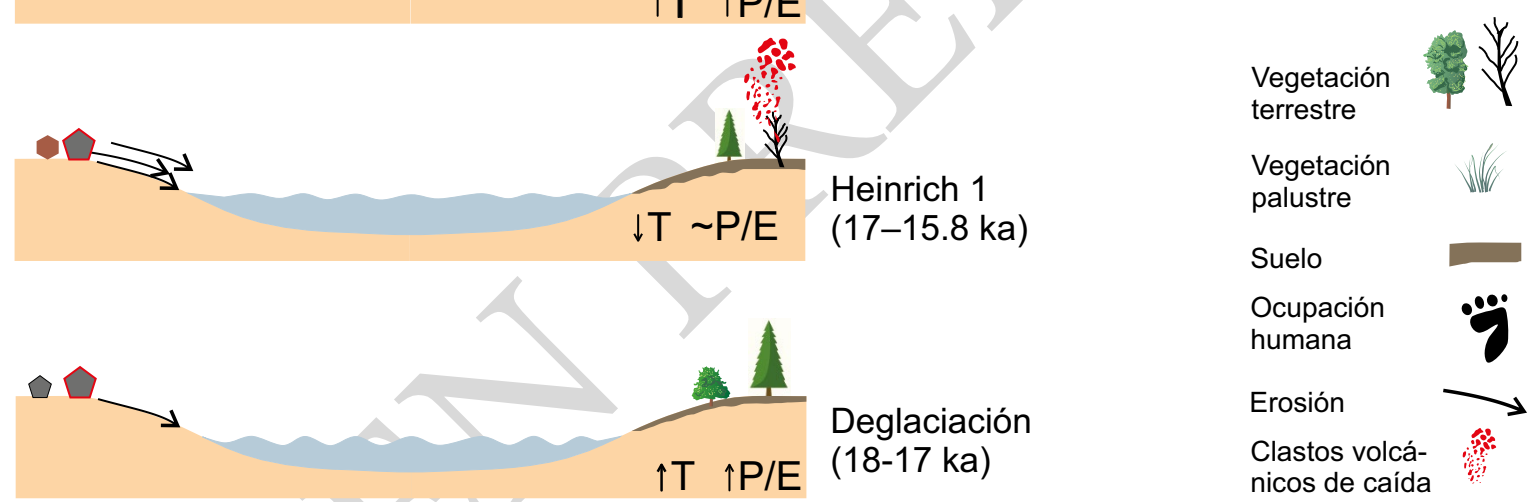

Figura 9. Esquema de la evolución paleoambiental del lago de Xochimilco que muestra las características de las principales fases identificadas. Deglaciación: temperatura (T) en incremento, balance precipitación/evaporación (P/E) en incremento, lago somero de agua dulce y fría, escasa cobertura vegetal y suelo, aporte limitado de clastos a la cuenca, mineralogía magnética dominada por Ti-magnetita parcialmente oxidada/maghemita y una contribución de partículas SP. Heinrich 1: T disminuye, $\mathrm{P} / \mathrm{E}$ variable, intensa actividad volcánica, incremento en la erosión, formación de hematita. Bølling/Allerød: T y P/E incrementan, expansión de vegetación terrestre, mayor desarrollo de suelos, formación de minerales pedogénicos. Younger Dryas: T y P/E disminuyen, contracción de vegetación terrestre, lago somero de agua dulce. Holoceno temprano: máximo de insolación de verano, condiciones de sequía, lago somero alcalino y salobre. Holoceno medio (8.27.1 ka): $\mathrm{P} / \mathrm{E}$ positivo, lago de agua dulce, máxima expansión de vegetación terrestre, desarrollo de suelos, condiciones favorables para ocupación humana. Holoceno medio (6-5 ka): aumento en la erosión, formación de bacterias magnetotácticas.

agua dulce. Estas características indican el retorno a condiciones más húmedas y un aumento en el nivel del lago, que fueron temporalmente interrumpidas por condiciones ligeramente más secas alrededor de los 6500 años cal AP, cuando se registra un breve incremento en la especie alcalífila Nitzschia amphibia y en CIT. Entre 7100 y 6200 años cal AP, el depósito del ooze de diatomeas diluye al resto de los componentes no silíceos.

Los últimos ca. 1200 años del registro (6200 a 5000 años cal AP), se caracterizaron por un marcado aumento en la sedimentación clástica y en los minerales ferrimagnéticos, y concentraciones relativamente bajas de diatomeas. Los conjuntos de diatomeas están dominados por especies de ambientes someros circumneutrales, con menores abundancias de especies alcalófilas. En la mineralogía magnética se identificó una componente de coercitividad intermedia que probablemente corresponda a maghemita o a magnetofósiles de alta coercitividad parcialmente oxidados, y una componente de mayor coercitividad interpretada como hematita ultrafina de baja coercitividad. Un ambiente lacustre litoral con rápida sedimentación y abundante vegetación 
pudo albergar las condiciones de baja concentración de oxígeno por descomposición de la materia orgánica, favorables para el desarrollo de bacterias magnetotácticas (Figura 9).

Durante este tiempo se ha documentado la existencia de ocupación humana del periodo precerámico (7000-2000 años a. C.) en los sitios de las zonas chinamperas al sur y sudoccidente del sitio de este estudio, en el ejido San Gregorio Atlapulco (Parsons et al., 1982). En esta zona se fechó por ${ }^{14} \mathrm{C}$ un estrato con abundantes restos líticos y faunísticos entre 5900 y 6200 años cal AP (McClung de Tapia y AcostaOchoa, 2015). Es probable que el paulatino poblamiento en la región y la consecuente alteración del paisaje se encuentren reflejados en los registros analizados, en particular a partir de la conversión del lago de aguas alcalinas y salobres a aguas dulces, como el incremento en la erosión en la parte superior de la secuencia.

\section{COMPARACIÓN CON REGISTROS REGIONALES}

El registro paleoclimático analizado en este trabajo muestra similitudes con los registros de Chalco y la cuenca del Lerma. Las condiciones frías de la deglaciación y sus variaciones tanto en temperatura como humedad, tales como los eventos $\mathrm{H} 1, \mathrm{~B} / \mathrm{A}$ y YD, se registran en las tres cuencas (Caballero et al., 2002; Lozano-García et al., 2015), en donde se reconoce la existencia de lagos someros de agua dulce. Hacia ca. 14300 años cal AP, tanto en Xochimilco como en Lerma se registra un breve y rápido episodio de bajos niveles lacustres seguido por el aumento en los mismos, centrado en el evento B/A.

Las características inferidas en Xochimilco de marcada evaporación y condiciones secas durante el Holoceno temprano coinciden con aquellas identificadas en las cuencas del centro de México, con bajos niveles lacustres: Chalco (Caballero y Ortega-Guerrero, 1998; Lozano-García et al., 2015), Texcoco (Bradbury, 1989; Lozano-García y Ortega-Guerrero, 1998), Tecocomulco (Caballero et al., 1999), Lerma (Caballero et al., 2002), Zacapu (Metcalfe, 1995) y Zirahuén (LozanoGarcía et al., 2013). La significativa abundancia de goethita/hematita durante este periodo ha sido ya documentada en la cuenca de Chalco (Ortega-Guerrero et al., 2000).

\section{CONCLUSIONES}

El análisis de indicadores múltiples del sitio XOC16-II proporciona una reconstrucción paleoambiental novedosa de la cuenca de Xochimilco. Este registro es relevante ya que ofrece información para una zona en la que se ha documentado una larga historia de ocupación humana con gran riqueza cultural que ha sido declarada patrimonio de la humanidad.

Las variaciones climáticas globales de escalas milenarias se identifican en las notables variaciones de la litología, materia orgánica, indicadores geoquímicos, propiedades magnéticas y asociaciones de diatomeas de la secuencia sedimentaria analizada.

Durante la deglaciación (18000-11700 años cal AP), la escasa cobertura de vegetación terrestre con limitado desarrollo de suelos favoreció un aporte variable y continuo de sedimentos a un lago somero de agua dulce de aguas más frías que las actuales. En este periodo se registró una actividad volcánica explosiva intensa, cuyos productos de caída controlaron la sedimentación clástica. A lo largo del evento Heinrich 1 (H1, 17500-15800 años cal AP), la disponibilidad de materiales volcánicos no consolidados y la contracción de la vegetación terrestre, resultaron en el incremento en la erosión. En la fase inicial templada del intervalo relativamente cálido Bølling/Allerød ( $c a$. 15500-14300 años cal AP), se infiere la existencia de una cubierta ve- getal reducida, con suelos bien drenados y una alternancia de periodos secos y húmedos, en los que el aporte clástico a un lago relativamente salino fue limitado. Durante la fase cálida Allerød (ca. 14300-13000 años cal AP), se documentan condiciones más húmedas, con mayor aporte de detritos al lago, mayor productividad biogénica y la expansión de la vegetación terrestre. Para el intervalo frío del Younger Dryas (YD, 13000-12000 años cal AP), las condiciones de sequía restringieron el aporte de detritos al lago y contrajeron la vegetación terrestre.

El Holoceno temprano (11700 años cal AP - 8200 años cal AP) está marcado por las condiciones más secas registradas en toda la secuencia, que coinciden con el máximo de insolación de verano para el hemisferio norte, alrededor de 10000 años cal AP. Durante este intervalo, las condiciones de alta evaporación redujeron del cuerpo lacustre, cuyas aguas se concentraron y permitieron el desarrollo de componentes calcáreos, y provocaron un aumento de incendios. A los 9500 años cal AP ocurrió un cambio a condiciones menos secas, que se interrumpió hacia 8520 años cal AP, cuando ocurrió un breve retorno a condiciones de sequía. Esta fluctuación pudo corresponder al episodio de enfriamiento ocurrido hacia 8200 años cal AP. La diacronía en el registro de Xochimilco puede deberse a las limitaciones del modelo de edad.

En el Holoceno medio, entre 8200-7100 años cal AP, el retorno a condiciones más húmedas ocasionó el desarrollo de suelos saturados con una extensa cubierta vegetal que redujo la erosión superficial y el establecimiento de un lago de agua dulce, condiciones que debieron favorecer el asentamiento de centros de población en los alrededores. Entre 6200 a 5000 años cal AP ocurre la mayor erosión, lo que puede ser reflejo del impacto humano. La rápida sedimentación en un ambiente lacustre con abundante materia orgánica fueron condiciones favorables para la formación de bacterias magnetotácticas.

\section{MATERIAL SUPLEMENTARIO}

Las Figura S1 y las Tablas S1 y S2 están disponibles en el portal web www.rmcg.unam.mx, en la tabla de contenido de este número.

\section{AGRADECIMIENTOS}

Este trabajo es parte de los proyectos UNAM-DGAPA- PAPIIT IN107416 e IN105918. Agradecemos el apoyo del Biol. Martín Hernández y el Laboratorio de Paleoecología, Paleoclimatologia y Cambio Climático (financiado por el proyecto UNAM-DGAPA PAPIIT IV100215) del Instituto de Geología de la Universidad Nacional Autónoma de México (UNAM) por la determinación de C y N. Al Laboratorio de Paleoceanografía y Paleoclimas del Instituto de Geofísica de la UNAM por los análisis de FRX. La medición de los ciclos de histéresis se realizó en el Institute for Rock Magnetism (IRM), University of Minnesota, con ayuda del Dr. Dario Bilardello y el Lic. Rodrigo Martínez. El IRM es apoyado por la National Science Foundation, Earth Science Division, y por la University of Minnesota. La Dra. Liseth Pérez y su grupo de trabajo del Instituto de Geología de la UNAM colaboró en la extracción y limpieza de ostrácodos para el fechamiento por ${ }^{14} \mathrm{C}$. El M. en C. Arnaldo Hernández elaboró el código de Matlab para la determinación de las temperaturas de Curie. M.A. Albarrán Santos e I.Y. Corona recibieron beca para realización de tesis de los proyectos PAPIIT IN107416 y IN105918, y del Instituto de Geofísica de la UNAM, respectivamente. Agradecemos el apoyo de las autoridades de la Secretaría del Medio Ambiente de la Ciudad de México, en particular a las del vivero Nezahualcóyotl, por las facilidades brindadas durante el trabajo de campo. Los autores agradecen los 
comentarios de dos revisores anónimos, que contribuyeron a mejorar sustancialmente este trabajo.

\section{REFERENCIAS}

Acosta-Ochoa, G., 2007, Las ocupaciones precerámicas de la cuenca de México. Del poblamiento las primeras sociedades agrícolas: Arqueoweb 8(2), 2.

Albarrán-Santos, M.A., 2018, Historia paleoambiental de la subcuenca de Xochimilco entre $c a .18$ y $5 \mathrm{ka} \mathrm{cal} \mathrm{AP:} \mathrm{magnetismo} \mathrm{ambiental} \mathrm{y} \mathrm{geoquímica}$ aplicados a la paleolimnología: Ciudad de México, Universidad Nacional Autónoma de México, tesis de licenciatura, 86 pp.

Arana-Salinas, L., Siebe, C., Macías, J.L., 2010, Dynamics of the ca. 4965 yr 14C BP "Ochre Pumice" Plinian eruption of Popocatépetl volcano, México: Journal of Volcanology and Geothermal Research, 192, 212-231.

Arce, J.L., Macías, J.L., Vázquez-Selem, L., 2003, The 10.5 ka Plinian eruption of Nevado de Toluca volcano, Mexico: stratigraphy and hazard implications: Geological Society of America Bulletin, 115(2), 230-248.

Arce, J.L., Macías, R., García-Palomo, A., Capra, L., Macías, J.L., Layer, P., Rueda, H., 2008, Late Pleistocene flank collapse of Zempoala Volcano (Central Mexico) and the role of fault reactivation: Journal of Volcanology and Geothermal Research, 177, 944-958.

Arce, J.L., Layer, P.W., Lassiter, J.C., Benowitz, J.A., Macías, J.L., RamírezEspinosa, J., 2013, ${ }^{40} \mathrm{Ar} /{ }^{39} \mathrm{Ar}$ dating, geochemistry, and isotopic analyses of the Quaternary Chichinautzin volcanic field, south of Mexico City: implications for timing, eruption rate, and distribution of volcanism: Bulletin of Volcanology, 75(12), 774. doi 10.1007/s00445-013-0774-6.

Barber, D.C., Dyke, A., Hillaire-Marcel, C., Jennings, A. E., Andrews, J.T., Kerwin, M. W., Bilodeau, G., McNeely, R., Southon, J., Morehead, M.D., Gagnon J.-M., 1999, Forcing of the cold event of 8,200 years ago by catastrophic drainage of Laurentide lakes: Nature, 400, 344-348.

Bloomfield, K., 1975, A late-Quaternary monogenetic volcano field in central Mexico: Geologische Rundschau, 64(1), 476-497.

Bloomfield, K., Valastro, S., 1974, Late Pleistocene eruptive history of Nevado de Toluca volcano, central Mexico: Geological Society of America Bulletin, $85,901-906$

Bradbury, J., 1989, Late Quaternary lacustrine paleoenvironments in the Cuenca de México: Quaternary Science Reviews, 8(1), 75-100.

Brown, E.T., Johnson, T.C., Scholz, C.A., Cohen, A.S., King, J.W., 2007, Abrupt change in tropical African climate linked to the bipolar seesaw over the past 55,000 years: Geophysics Research Letters, 34. doi:10.1029/2007GL031240.

Bronk Ramsey, C., 2009, Bayesian analysis of radiocarbon dates: Radiocarbon, 51(01), 337-360.

Caballero, M., Ortega-Guerrero, B., 1998, lake levels since about 40,000 years ago at lake Chalco, near Mexico City: Quaternary Research, 50(1), 69-79.

Caballero, M., Lozano-García, S., Ortega-Guerrero, B., Urrutia-Fucugauchi, J., Macías, J.L., 1999, Environmental characteristics of Lake Tecocomulco, northern basin of Mexico, for the last 50,000 years: Journal of Paleolimnology, 22, 399-411.

Caballero, M., Ortega, B., Valadez, F., Metcalfe, S., Macías, J.L., Sugiura, Y., 2002, Sta. Cruz Atizapán: a 22-ka lake level record and climatic implications for the late Holocene human occupation in the Upper Lerma Basin, Central Mexico: Palaeogeography, Palaeoclimatology, Palaeoecology, 186, 217-235.

Capra, L., Carreras, L.M., Arce, J.L., Macías, J.L., 2006, The Lower Toluca Pumice: a ca. 21,700 yr BP Plinian eruption of Nevado de Toluca volcano, México, en Siebe, C., Macías, J.L., Aguirre-Díaz, G.J., (eds.), Neogenequaternary Continental Margin Volcanism: a Perspective from México: Geological Society of America Special Paper 402, Penrose Conference Series,155-173. http://dx.doi.org/10.1130/2006.2402(07).

Clark, P.U., Dyke, A.S., Shakun, J.D., Carlson, A.E., Clark, J., Wohlfarth, B., Mitrovica, J.X., Hostetler, S.W., McCabe, A.M., 2009, The last glacial maximum: Science, 325, 710-714.

Corella, J., Brauer, A., Mangili, C., Rull, V., Vegas-Vilarrúbia, T., Morellón, M., Valero-Garcés, B., 2012, The 1.5-ka varved record of Lake Montcortès (southern Pyrenees, NE Spain): Quaternary Research, 78, 323-332. DOI:10.1016/j.yqres.2012.06.002.

Cornell, R.M., Schwertmann, U., 2003, The Iron Oxides: Structures, Properties, Reactions, Occurences, and Uses: Cambridge, England, Wiley-VCH,
664 pp.

Correa-Metrio, A., Bush, M.B., Lozano-García, S., Sosa-Nájera, S., 2013, Millennial-scale temperature change velocity in the continental northern Neotropics: PLoS ONE 8, e81958.

Dearing, J.A., 1994, Environmental magnetic susceptibility. Using the Bartington MS2 system: England, Chi Publishing, 104 pp. EN TABLA S1

Egli, R., 2004, Characterization of individual rock magnetic components by analysis of remanence curves, 1. Unmixing natural sediments: Studia Geophysica et Geodaetica, 48, 391-446.

Evans, M., Heller, F., 2003, Environmental Magnetism. Principles and Applications of Environmagnetics: United States of America, Elsevier Science, 299 pp.

Funk, J.A., von Dobeneck, T., Reitz, A., 2004, Integrated rock magnetic and geochemical quantification of redoxmorphic iron mineral diagenesis in Late Quaternary sediments from the equatorial Atlantic, in Wefer, G., Mulitza, S., Ratmeyer, V. (eds.), The South Atlantic in the Late Quaternary: Dordrecht, Holland, Springer, 237-260.

García-Palomo, A., Macías, J.L., Arce, J.L., Capra, L., Garduño, V.H., Espíndola J.M., 2002, Geology of Nevado de Toluca Volcano and surrounding areas, central Mexico: Geological Society of America, Map and Chart Series MCH089.

García-Palomo, A., Zamorano, J., López-Miguel, C., Galván-García, A., CarlosValerio, V., Ortega, R., Macías, J., 2008, El arreglo morfoestructural de la Sierra de Las Cruces, México central: Revista Mexicana de Ciencias Geológicas, 25(1), 158-178.

Grimm, E., 2004, Tilia and TGView 2.0.2 Illinois State Museum: Springfield, Illinois, Research and Collection Center.

Guilbaud, M.N., Arana-Salinas, L., Siebe, C., Barba-Pingarrón, L.A., Ortiz, A., 2015, Volcanic stratigraphy of a high-altitude mammuthus columbi (Tlacotenco, sierra Chichinautzin), central México: Bulletin of Volcanology, 77(3), 17.

Heinrich, H., 1988, Origin and consequences of cyclic ice rafting in the northeast Atlantic Ocean during the past 130,000 years: Quaternary Research, 29, 142-152.

INEGI (Instituto Nacional de Estadística y Geografía), 2011, Censo de población y vivienda 2010, disponible en <http://www.inegi.org.mx/est/contenidos/ proyectos/ccpv/cpv2010/>, consulta: 6 de enero de 2018.

Jaimes-Viera, C., Martin del Pozzo, A.L., Layer, P.W., Benowitz, J.A., NietoTorres, A., 2018, Timing the evolution of a monogenetic volcanic field: Sierra Chichinautzin, Central Mexico: Journal of Volcanology and Geothermal Research, 356, 225-242.

Jouve, G., Francus, P., Lamoureux, S., Provencher-Nolet, L., Hahn, A., Haberzettl, T., Fortin, D., Nuttin, L., The PASADO Science Team, 2013, Microsedimentological characterization using image analysis and $\mu$ XRF as indicators of sedimentary processes and climate changes during Late glacial at Laguna Potrok Aike, Santa Cruz, Argentina: Quaternary Science Reviews, 71, 191-204. doi:10.1016/j.quascirev.2012.06.03

Kampf, N., Schwertmann, U., 1983, Goethite and hematite in a climosequence in southern Brazil and their application in classification of kaolinitic soils: Geoderma, 29, 27-39.

Krammer, K., Lange-Bertalot, H., 1986, Süsswasserflora von Mitteleuropa Bacillariophyceae. 2/1, Naviculaceae, Gustav Fischer Verlag, Stuttgart, $876 \mathrm{pp}$.

Krammer, K., Lange-Bertalot, H., 1988, Süsswasserflora von Mitteleuropa Bacillariophyceae. 2/2, Bacillariaceae, Epithemiaceae, Surirellaceae, Gustav Fischer Verlag, Stuttgart, 596 pp.

Krammer, K., Lange-Bertalot, H., 1991a, Süsswasserflora von Mitteleuropa Bacillariophyceae. 2/3, Centrales, Fragilariaceae, Eunotiaceae, Gustav Fischer Verlag, Stuttgart, 576 pp.

Krammer, K., Lange-Bertalot, H., 1991b, Süsswasserflora von Mitteleuropa Bacillariophyceae. 2/4, Achnanthaceae, Kritische Ergänzungen zu Navicula (Lineolatae) und Gomphonema, Gustav Fischer Verlag, Stuttgart, 437 pp.

Lascu, I., Wohlfarth, B., Onac, B., Bjorck, S., Kromer, B., 2015, A Late Glacial paleolake record from an up-dammed river valley in northern Transylvania, Romania: Quaternary International, 388, 87-96.

Liu, Q., Banerjee, S.K., Jackson, M.J., 2002, A new method in mineral magnetism for the separation of weak antiferromagnetic signal from a strong ferrimagnetic background: Geophysics Research Letters, 29, 1-4.

Liu, Q., Roberts, A.P., Torrent, J., Horng, C.-S., Larrasoaña, J.C., 2007, What 
do the HIRM and S-ratio really measure in environmental magnetism?: Geochemistry, Geophysics, Geosystems, 8(9), 1-10.

Liu, Q., Roberts, A.P., Larrasoaña, J.C., Banerjee, S.K., Guyodo, Y., Tauxe, L., Oldfield, F., 2012, Environmental magnetism: Principles and applications: Reviews of Geophysics, 50, 1-50.

Lozano-García, M.S., Ortega-Guerrero, B., 1998, Late Quaternary environmental changes of the central part of the Basin of Mexico; correlation between Texcoco and Chalco basins: Review of Palaeobotany and Palynology, 99, 77-93.

Lozano-García, M.S., Ortega-Guerrero, B., Caballero-Miranda, M., UrrutiaFucugauchi, J., 1993, Late Pleistocene and Holocene paleoenvironments of Chalco lake, central Mexico: Quaternary Research, 40(3), 332-342.

Lozano-García, S., Torres-Rodríguez, E., Ortega, B., Vázquez, G., Caballero, M., 2013, Ecosystem responses to climate and disturbances in western central Mexico during the late Pleistocene and Holocene: Palaeogeography, Palaeoclimatology, Palaeoecology, 370, 184-195.

Lozano-García, S., Ortega, B., Roy, P.D., Beramendi-Orosco, L., Caballero, M., 2015, Climatic variability in the northern sector of the American tropics since the latest MIS 3: Quaternary Research, 84(2), 262-271.

Macías, J.L., García-Palomo, A., Arce, J.L., Siebe, C., Espíndola, J.M., Komorowski, J.C., Scott, K.M., 1997, Late Pleistocene-Holocene cataclysmic eruptions at Nevado de Toluca and Jocotitlán volcanoes, central México, in Kowallis, B.J. (eds.), Proterozoic to recent stratigraphy, tectonics, and volcanology, Utah, Nevada, southern Idaho and central México: Brigham Young University Geology Studies, 493-528.

Maher, B., Thompson, R., 1995, Paleorainfall reconstructions from pedogenic magnetic susceptibility variations in the Chinese loess and paleosols: Quaternary Research, 44, 383-391.

Martin del Pozzo, A.L., 1982, Monogenetic vulcanism in sierra Chichinautzin, Mexico: Bulletin of Volcanology, 45(1), 9-24.

Maxbauer, D.P., Feinberg, J.M., Fox, D.L., 2016, MAX UnMix: A wb application for unmixing magnetic coercivity distributions: Computers \& Geosciences, $95,140-145$.

McClung de Tapia, E., Acosta-Ochoa, G., 2015, La ocupación del periodo de agricultura temprana en Xochimilco ( $c a .4200-400$ a.n.e.): Anales de Antropología, 49-II, 229-315.

Metcalfe, S.E., 1995, Holocene environmental change in the Zacapu Basin, Mexico: a diatom-based record: Holocene, 5, 196-208.

Mora-Alvarez, G., Caballero-Miranda, C., Urrutia-Fucugauchi, J., Uchiumi, S., 1991, Southward migration of volcanic activity in the Sierra Las Cruces, basin of Mexico? A preliminary K-Ar dating and paleomagnetic study: Geofísica Internacional, 30(2), 61-70.

Myrbo, A., 2007, Smear slide identifications: the practical basics: http://lrc. geo.umn.edu/laccore/assets/pdf/sops/smear_slide_basics.pdf. Consulta: septiembre de 2017.

Ortega-Guerrero, B., Newton, A.J., 1998, Geochemical characterization of late Pleistocene and Holocene tephra layers from the Basin of Mexico, Central Mexico: Quaternary Research, 50(1), 90-106.

Ortega-Guerrero, B., Thompson, R., Urrutia-Fucugauchi, J., 2000, Magnetic properties of lake sediments from Lake Chalco, central Mexico, and their palaeoenvironmental implications: Journal of Quaternary Science, 15(2), 127-140.

Ortega-Guerrero, B., Lozano-García, M., Caballero, M., Herrera-Hernández, D.A., 2015, Historia de la evolución deposicional del lago de Chalco, México, desde el MIS 3: Boletín de la Sociedad Geológica Mexicana, 67(2), 185-201.

Ortega-Guerrero, B., Caballero-García, L., Linares-López, C., 2018, Tephrostratigraphy of the late Quaternary record from Lake Chalco, central México: Journal of South American Earth Sciences, 81, 122-140.

Ortiz-Enríquez, O., 2017, Petrografía y geoquímica del vulcanismo monogenético de la sierra de Santa Catarina, cuenca de México: Taxco El Viejo, Universidad Autónoma de Guerrero, tesis de licenciatura, 138 pp.

Osete, M.L., Ruiz-Martínez, V.C., Caballero, C., Galindo, C., Urrutia-Fucugauchi, J., Tarling, D.H., 2000, Southward migration of continental volcanic activity in the Sierra de Las Cruces, Mexico: paleomagnetic and radiometric evidence: Tectonophysics, 318, 201-215
Özdemir, O., Dunlop, D.J., 2014, Hysteresis and coercivity of hematite: Journal of Geophysical Research, Solid Earth, 119, 2582-2594.

Palerm, A., Wolf, E., 1972, Agricultura y civilización en Mesoamérica: México, Ed. Sep-Setentas, 32, 215 pp.

Patrick, R., Reimer, C.W., 1966, The diatoms of the United States: Monographs of the Philadelphia Academy of Natural Sciences, 1, monograph 13, $688 \mathrm{pp}$.

Parsons, J., Brumfiel, E., Parsons, M.H., Wilson, D.J., 1982, Prehispanic settlement patterns in the southern Valley of Mexico, the ChalcoXochimilco region: Ann Arbor, University of Michigan, Memoirs of the Museum of Anthropology, 14, 504 pp.

Peters, C., Dekkers, M.J., 2003, Selected room temperature magnetic parameters as a function of mineralogy, concentration and grain size: Physics and Chemistry of the Earth, 28, 659-667.

Reimer, P.J., Bard, E., Bayliss, A., Beck, J.W., Blackwell, P.G., Bronk Ramsey, C., Buck, C.E., Cheng, H., Edwards, R.L., Friedrich,M., Grootes, P.M., Guilderson, T.P., Haflidason, H., Hajdas, I., Hatté, C., Heaton, T.J., Hoffmann, D.L., Hogg, A.G., Hughen, K.A., Kaiser, K.F., Kromer, B., Manning, S.W., Niu, M., Reimer, R.W., Richards, D.A., Scott, E.M., Southon, J.R., Staff, R.A., Turney, C.S.M., van der Plicht, J., 2013, IntCal13 and Marine13 Radiocarbon Age Calibration Curves 0-50,000 Years cal BP: Radiocarbon, 55, 1869-1887.

Romero-Terán, E., 2001, Geología del Complejo Volcánico San Miguel, al sur poniente de la Cuenca de México: México, D.F., Universidad Nacional Autónoma de México, tesis de maestría, 40 pp.

Schnurrenberger, D., Russell, J., Kelts, K., 2003, Classification of lacustrine sediments based on sedimentary components: Journal of Paleolimnology, 29(2), 141-154

Siebe, C., 2000, Age and archaeological implications of Xitle volcano, southwestern Basin of Mexico-City: Journal of Volcanology and Geothermal Research, 104(1), 45-64.

Siebe, C., Macías, J.L., Abrams, M., Rodríguez, S., Castro, R., 1997, Catastrophic Prehistoric eruptions at Popocatepetl and Quaternary explosive volcanism in the Serdán-Oriental Basin, East-Central Mexico (fieltrip guidebook), in International Association of Volcanology and Chemistry of the Earth's Interior (IAVCEI) General Assembly: Puerto Vallarta, Jalisco, México, 19-24.

Siebe, C., Schaaf, P., Urrutia-Fucugauchi, J., 1999, Mammoth bones embedded in a late Pleistocene lahar from Popocatépetl volcano, near Tocuila, central México: Geological Society of America Bulletin, 111(10), 1550-1562.

Siebe, C., Rodríguez-Lara, V., Schaaf, P., Abrams, M., 2004, Radiocarbon ages of Holocene Pelado, Guespalapa, and Chichinautzin scoria cones, south of Mexico-City: implications for archaeology and future hazards: Bulletin of Volcanology, 66, 203-225.

Siebe, C., Arana-Salinas, L., Abrams, M., 2005, Geology and radiocarbon ages of Tláloc, Tlacotenco, Cuauhtzin, Hijo del Cuauhtzin, Teuhtli, and Ocusacayo monogenetic volcanoes in the central part of the Sierra Chichinautzin, México: Journal of Volcanology and Geothermal Research, 141(3), 225-243.

Sosa-Ceballos, G., Gardner, J.E., Siebe, C., Macías, J.L., 2012, A caldera-forming eruption $\sim 14,10014 \mathrm{Cyr} \mathrm{BP}$ at Popocatépetl volcano, México: insights from eruption dynamics and magma mixing: Journal of Volcanology and Geothermal Research, 213, 27-40.

Tauxe, L., 1998, Paleomagnetic principles and practice: Dordrecht, Holland, Kluwer Academic Publishers, 299 pp.

Torres-Rodríguez, E., Lozano-García, S., Roy, P., Ortega, B., Beramendi-Orosco, L., Correa-Metrio, A., Caballero, M., 2015, Last Glacial droughts and fire regimes in the central Mexican highlands: Journal of Quaternary Science, $30(1), 88-99$.

Manuscrito recibido: marzo 20, 2018

Manuscrito corregido recibido: agosto 9, 2018

Manuscrito aceptado: agosto 10, 2018 